\title{
Neutrophil-to-lymphocyte ratio, past, present and future perspectives
}

\author{
Zahorec R \\ 2nd Department Anesthesiology and Intensive Medicine, Medical Faculty, Comenius University, \\ Bratislava, St. Elizabeth's Cancer Institute, Bratislava, Slovakia.rzahorec@ousa.sk
}

\begin{abstract}
In the review we analyzed short history of the establishment of a novel hematological parameter for systemic inflammation and stress coined as a neutrophil to lymphocyte ratio (NLR). Today NLR is widely used across almost all medical disciplines as a reliable and easy available marker of immune response to various infectious and non-infectious stimuli. We analyzed the immunological and biological aspects of dynamic changes of neutrophil granulocytes and lymphocytes in circulating blood during endocrine stress, dysbalance of autonomic nervous system and systemic inflammation. NLR reflects online dynamic relationship between innate (neutrophils) and adaptive cellular immune response (lymphocytes) during illness and various pathological states. NLR is influenced by many conditions including age, rice, medication, chronic disease like coronary heart disease, stroke, diabetes, obesity, psychiatric diagnosis, cancer of solid organs, anemia and stress. A normal range of NLR is between $1-2$, the values higher than 3.0 and below 0.7 in adults are pathological. NLR in a grey zone between 2.3-3.0 may serve as early warning of pathological state or process such like cancer, atherosclerosis, infection, inflammation, psychiatric disorders and stress. NLR is used as a reliable and cheap marker of ongoing cancerrelated inflammation and a valid indicator of prognosis of solid tumors. Majority of meta-analyses have explored the prognostic value of NLR in various solid tumors and have found out the cut-off value of NLR above 3.0 (IQR 2.5-5.0). We summarized its privilege in oncology: NLR may be used for stratification of cancer, correlates with the tumor size, stage of tumors, metastatic potential and lymphatic invasion. NLR has independent prognostic role regarding overall, cancer free and cancer-specific survival. It is useful for monitoring oncological therapy, including biological and immune check point inhibitors treatment. NLR is a very sensitive indicator of infection, inflammation and sepsis, validated in numerous studies. Clinical research confirmed the sensitivity of NLR for diagnosis/stratification of systemic infection, sepsis, bacteremia as well as its robust predictive and prognostic value. NLR should be investigated daily, and follow-up its absolute values and dynamic course in acute disease or critical illness. The severity of critical illness, the level of stress and serious inflammation is expressed by dramatic increasing of NLR values above $11 \geq 17$, or even higher than 30 . Improving the clinical course of sepsis, critical illness, lower risk of mortality are associated with decline of NLR values below 7. NLR is helpful in differentiating more severe disease versus milder one. NLR is cheap, simple, fast responding and easy available parameter of stress and inflammation with high sensitivity and low specificity, it should be used routinely in emergency departments, ICUs, in acute medicine including surgery, orthopedics, traumatology, cardiology, neurology, psychiatry and even oncology. Dynamic changes of NLR precede the clinical state for several hours and may warn clinicians about the ongoing pathological process early. NLR is a novel perspective marker of cellular immune activation, a valid index of stress and systemic inflammation, which open a new dimension for clinical medicine, for better understanding of the biology of inflammation, coupling and antagonism between innate and adaptive immunity and its clinical consequences for health and disease (Tab. 8, Fig. 3, Ref. 151). Text in PDF www.elis.sk KEYWORDS: neutrophil-to-lymphocyte ratio, systemic inflammation, immune-inflammatory response, endocrinne stress.
\end{abstract}

\section{Simplex sigillum veri \\ Introduction}

Twenty years ago, we established a new parameter of immuneinflammatory reaction and neuro-endocrine stress, which is now coined as a neutrophil-to-lymphocyte ratio (NLR) (Zahorec, 2001).

2nd Department Anesthesiology and Intensive Medicine, Medical Faculty, Comenius University, Bratislava, St. Elizabeth's Cancer Institute, Bratislava, Slovakia

Address for correspondence: R. Zahorec, Ass Prof, MD, PhD, Medical Faculty, Comenius University, St. Elizabeth's Cancer Institute, Heydukova 10, SK-812 50 Bratislava, Slovakia.

\section{A short history of invention of NLR}

In the period of 1998-2000. we explored new biomarkers of sepsis, namely procalcitonin and neopterin for the diagnosis of severe bacterial or viral infection in ICU setting. We studied the kinetics of procalcitonin, a valid biomarker of sepsis and systemic infection, on a cohort of 90 ICU cancer patients at the department of anesthesiology and intensive medicine, St. Elizabeth's Cancer Institute, Bratislava, Slovakia. We measured several blood parameters of systemic inflammation, such as acute phase proteins, thrombocyte and leukocyte counts, including white blood cell differential populations, together with the clinical course of critically ill patients. We were focused on the systemic inflammatory 
response syndrome (SIRS) after elective cancer surgery, referred to as post-surgical SIRS, and biomarkers of sepsis during the abdominal sepsis syndrome (Zahorec et al, 2000). We observed a significant elevation of serum procalcitonin in the morning of the first post-operative day (mean peak value $1.5 \mathrm{ng} / \mathrm{ml}$, median $1.3 \mathrm{ng} /$ $\mathrm{ml}$ ) and peak values of C-reactive protein on the second postoperative day. The interesting observation was that there was a profound decline in the lymphocyte count after surgery (induced by "surgical SIRS") and a more profound deep lymphocytopenia during bacteremia, severe sepsis and septic shock (Zahorec et al, 2000).

We suggested that SIRS criteria defined by R. Bone (1992) may be useful and more reliable. Instead of WBC count which has low sensitivity and specificity in the diagnosis of sepsis, a new, more specific marker and a more sensitive hematological parameter can be used, namely serum procalcitonin and lymphocyte count, respectively (Zahorec, 2000). In many clinical settings of SIRS (after multiple trauma, acute pancreatitis, cardiogenic shock, postresuscitation disease, burns injury) and various critical illnesses (abdominal sepsis, ARDS, septic shock, hemorrhagic shock), we observed a significant elevation in serum procalcitonin, namely 10-100-fold above normal values together with marked lymphocytopenia (Zahorec 2000 a, b, c). In November, 2000, professor Lamy (Liege, Belgium) attended Bratislava with a lecture on experimental and clinical issues of sepsis. He mentioned one interesting experimental trial which has been conducted on human volunteers and was exploring the effect of an intravenous endotoxin on the synthesis of adhesion molecules (Jilma et al, 1999). They followed up dynamic changes in neutrophil granulocytes and population of lymphocytes during human endotoxemia by serial investigations of complete blood count differential during 24 hours after administration of $4 \mathrm{ng} / \mathrm{kg}$ of lipopolysaccharide (Jilma et al, 1999). One hour after the administration of the endotoxin, they observed a sudden drop in the neutrophil count, which was followed by a steep increase in the neutrophil count up to $8,000-10,000 / \mu 1$ with the maximum peak taking place during the period of 4-6 hours after endotoxin administration, and a profound decline in the lymphocyte cell count in peripheral blood. In conclusion, the acute experimental endotoxemia was associated with significant neutrophilia (high neutrophil count of over $8,000 / \mu 1)$ and profound lymphocytopenia $(<600-500 / \mu 1)$. These results published by Jilma et al (1999) were a strong motivation (first step) for further research aimed at better understanding of this fascinating phenomenon - acute dynamic changes in circulating neutrophil and lymphocyte populations during the course of endotoxemia, SIRS, and/or sepsis.

The second step was the article by Elebute and Stoner (1983) who established a sepsis score to measure the grade of sepsis syndrome using Bayesian method. The wisdom of their first sentence is crucial: "It is frequently said, and with some truth, that You cannot begin to investigate something until you can measure it" (Elebute and Stoner, 1983). The third stimulus was the article by Jahangiri (1990) demonstrating the association between the severity of lymphocytopenia and severity of the clinical course of acute appendicitis proved by histopathological findings. The most profound lymphopenia was associated with gangrenous ap-

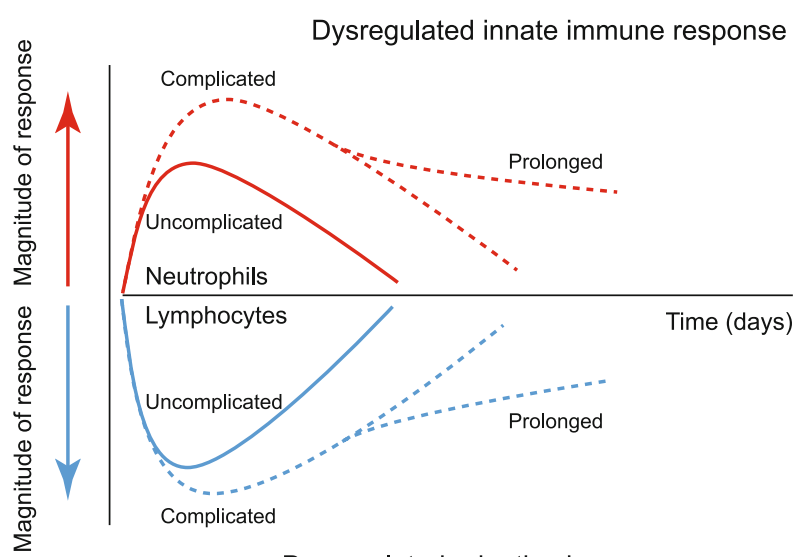

Dysregulated adaptive immune response

Fig. 1. Neutrophil-lymphocyte ratio reflects Cellular Immune Response to the supraphysiological insults as an interaction between innate (neutrophil granulocytes - red lines) and adaptive immune system (lymphocytes - blue lines) regarding physiological response (healing and recovery) and pathophysiological response (complicated - hyperinflammation „,cytokine storm“, or prolonged inflammation or prolonged immunosuppression, ), stimulated by Hotchkiss et al, 2016.

pendicitis. We conducted a pilot observational study on a cohort of 90 ICU cancer patients and observed a pattern of dynamics of elevation in the neutrophil count and decline in the lymphocyte count that was identical to that observed by Jilma et al (1999) after elective major abdominal surgery, sepsis and bacteremia. The most severe and marked elevation of neutrophil counts and very deep decline in lymphocyte counts were observed in association with most severe critical illnesses such as septic shock, hemorrhagic shock, multiple trauma, and acute pancreatitis (Zahorec, 2001). The most notable observation was that the dynamic changes in circulating WBC populations counts, namely the dramatic increase in circulating neutrophil count and very profound decline in the lymphocyte count, both took place simultaneously, "handin-hand", but in opposite directions. This divergent course of the latter leukocyte populations should be expressed by a number that would measure the severity of immune-inflammatory response to stress (Zahorec, 2001). Our results of clinical single-center trial together with previous observations that both neutrophilia and lymphocytopenia reflect the natural physiological response of circulating leukocytes to stress, injury, trauma, major surgery, bacteremia, systemic inflammation, SIRS and sepsis raise the question as to how to express this phenomenon. We found out that the optimal expression of the relation between dynamic changes of neutrophils and lymphocytes would be their ratio. We suggested the neutrophil-to-lymphocyte ratio as the most appropriate, simple and reliable parameter of the intensity of neuroendocrine stress and immune-inflammatory response, referred to as neutrophil/lymphocyte stress factor (NLSF). The ratio is the best expression of the tight functional relation between two fundamental immunocompetent leukocyte populations, i.e, neutrophil granulocytes (innate immune system) and lymphocytes (adaptive immune system) (Fig. 1). The neutrophil-to-lymphocyte ratio (NLR) is easily obtained by 
474-488

Tab. 1. Causes of neutrophilia (high and increased neutrophil count) and lymphocytopenia during stress, trauma, surgery, systemic infection, inflammation, sepsis, bacteremia and critical illness.

\begin{tabular}{|c|c|c|}
\hline $\begin{array}{l}\text { Activity/Leukocyte population during stress } \\
\text { and inflammation }\end{array}$ & $\begin{array}{l}\text { Increase in neutrophil granulocytes count in } \\
\text { the peripheral blood }\end{array}$ & $\begin{array}{l}\text { Decrease in lymphocyte count } \\
\text { (lymphocytopenia in the circulating blood) }\end{array}$ \\
\hline $\begin{array}{l}\text { Reticulo-endothelial system, endothelial } \\
\text { glycocalyx activity }\end{array}$ & Demargination & Margination \\
\hline Bone marrow & $\begin{array}{l}\text { Increased release, mobilization to blood } \\
\text { circulation, immature bands }\end{array}$ & Low release, demobilization \\
\hline Lymphoid tissue, lymphatic nodes, spleen & Distribution to blood circulation & $\begin{array}{l}\text { Redistribution, accumulation in lymphatic } \\
\text { tissue, lymph nodes and interstitium }\end{array}$ \\
\hline $\begin{array}{l}\text { Sympathetic activation/ stimulation of } \\
\text { sympathetic ANS }\end{array}$ & $\begin{array}{l}\text { Increase in mobilization and Neu count } \\
\text { in the blood, increase in activity of innate } \\
\text { immune response }\end{array}$ & $\begin{array}{l}\text { Lymphopenia, immunosuppression of } \\
\text { adaptive immune response }\end{array}$ \\
\hline Catecholamines: noradrenalin adrenalin & $\begin{array}{l}\text { Increase in release, mobilization and } \\
\text { increase in neutrophil count in the blood }\end{array}$ & $\begin{array}{l}\text { Decrease in count and activity of } \\
\text { lymphocytes, depressed adaptive immune } \\
\text { response }\end{array}$ \\
\hline $\begin{array}{l}\text { Cortisol and stimulation of parasympathetic } \\
\text { nervous system }\end{array}$ & Downregulation of inflammation & $\begin{array}{l}\text { Decrease in number of circulating } \\
\text { lymphocytes in the blood }\end{array}$ \\
\hline Apoptosis & $\begin{array}{l}\text { Delayed apoptosis, prolonged half-life of } \\
\text { neutrophils }\end{array}$ & $\begin{array}{l}\text { Accelerated apoptosis, shorten half-life of } \\
\text { lymphocyte }\end{array}$ \\
\hline
\end{tabular}

dividing the absolute neutrophil count by absolute lymphocyte count from peripheral complete blood counts. Originally, NLR has been suggested as a simple index of the systemic inflammatory response syndrome (SIRS) and stress in critically ill patients, to evaluate the severity of sepsis and systemic infection, including bacteremia (Zahorec, 2001).

\section{Physiology and pathophysiology of neutrophilia and lympho- cytopenia, expressed by neutrophil-to-lymphocyte ratio}

Neutrophilia and lymphocytopenia per se were observed after trauma, major surgery and studied separately at the end of 20th century. Major surgery evokes an endocrine stress response, characterized by an increase in serum cortisol, prolactin, plasma adrenaline and noradrenaline (Dionigi et al, 1994). Furthermore, surgical stress was accompanied by lymphopenia and granulocytosis in peripheral blood. The changes in peripheral white blood cells have been demonstrated after surgery as well as after cortisol infusion in experiments on rabbits. Lymphocytes were isolated from peripheral venous blood, labelled with indium-111-tropolene and reinjected intravenously into the rabbits. The redistribution of lymphocytes was imaged with a gamma-ray camera and calculated with a connected computer 2, 4 and 7 hours after the skin incision. The results indicate that major surgery induces a redistribution of lymphocytes from peripheral blood to the lymphatic tissue. Margination and redistribution are mostly responsible for lymphopenia in peripheral venous blood (Toft et al, 1993). Dionigi (1994) first noticed that lymphopenia during major surgery is due to physiological response of lymphocyte population to high serum levels of cortisol, prolactin and catecholamines. These observations were confirmed recently by another experimental study exploring the effects of stress hormones on the key immuno-competent cell populations, i.e, on neutrophil granulocytes and lymphocytes. Castrated male pigs $(n=34)$ were treated with physiological doses of either adrenaline, noradrenaline, or cortisol via i.v. in- fusion for $48 \mathrm{~h}$. Blood samples were collected before treatment $(-24 \mathrm{~h}, 0 \mathrm{~h})$, during treatment $(+2 \mathrm{~h},+24 \mathrm{~h},+48 \mathrm{~h})$, and at hour 72 after the infusion. The pigs receiving cortisol showed strongly decreased adaptive immune cell numbers (marked lymphopenia) and increased counts of neutrophils (significant neutrophilia). The catecholamine effects on immuno-competent cell numbers were mostly similar to cortisol in direction but smaller in intensity and duration. These findings indicate a shift from adaptive to innate immunity in stressful situations (Reiske et al, 2020). This general and natural physiologic reaction of the immune system to the supra-physiologic insults governed by the vegetative nervous system (interaction of sympathetic and parasympathetic autonomous nerve regulation modes) and endocrine system (the role of stress hormones including catecholamines, cortisol, prolactin) is conserved by evolution. Neutrophils play a pivotal role in the innate immune response including phagocytosis, and release of a variety of cytokines and molecule mediators. Lymphocytopenia is a hallmark of stress while inflammation is due to demargination, redistribution and accelerated apoptosis. NLR indicates the balance between innate and adaptive immune responses and it is an excellent indicator of inflammation and stress together (Fig.1). The opposite changes in neutrophil and lymphocyte counts are a multifactorial dynamic process depending on finetuning and regulation of various immunologic, neuroendocrine, humoral and biologic processes such as margination/ demargination, mobilization/redistribution, accelerated/delayed apoptosis, influence of stress hormones and sympathetic/parasympathetic imbalance of the vegetative nervous system (Tab. 1). This observation is supported by the systems biology and by theory of endobiogeny. K. Hedayat (2020) applied the theory of endobiogeny as a global system approach to living systems. According to this theory, the neuroendocrinne system is the manager of metabolism. The autonomic nervous system calibrates and sequences timing, duration, amplitude and intensity of endocrine function, and endocrinne system manages the coherency of metabolic activity across all 
Tab. 2. Normal values of neutrophil-to-lymphocyte ratio in healthy adults of different races across the world, normal NLR median: 1.65 (range 1.2-2.15).

\begin{tabular}{lccc}
\hline Author, Year, Country & $\begin{array}{c}\text { NLR }(1.2-1.65-2.15) \\
\text { Mean value } \pm \text { SD }\end{array}$ & Reference range of NLR & Number of participants, rice \\
\hline Azab et al, 2014, USA, New York & $\mathbf{2 . 1 5}(1.5-2.9)$ & $\mathbf{1 . 7 1 - 2 . 2 8}(-2.4)$ & 9,427 adults, Latinos, Caucasians, African Americans, \\
Yanti et al, 2016, Indonesia & $\mathbf{1 . 9 5}(1.35-2.17)$ & $\mathbf{1 . 1 5}-\mathbf{4 . 0 9}$ & 265 young Indonesian adults; 21 y \\
Forget et al, 2017, Brusel, Belgium & $\mathbf{1 . 6 5}(0.78-3.53)$ & $\mathbf{0 . 8}-\mathbf{3 . 5}$ & 413 healthy adults, 18-66 y from Brussels region \\
Mohamed et al, 2017, Sudán, Chartúm & $\mathbf{1 . 2}(0.75-1.65)$ & $\mathbf{0 . 7 5}-\mathbf{1 . 9}$ & 300 black Sudanese adults, age 5-85 y \\
Aydin et al, 2015, Turkey & $\mathbf{1 . 9}(1.1-2.2)$ & $\mathbf{1 . 0}-\mathbf{2 . 3}$ & Turkey \\
Lee et al, 2018 Soul, Korea & $\mathbf{1 . 6 5}(0.86-2.44)$ & $\mathbf{0 . 4}-\mathbf{3 . 1 9}$ & 12,160 Korean citizens \\
\hline
\end{tabular}

units of function based on three qualities: 1) constancy of action, 2) ubiquity of action, 3) autoregulation (Hedayat, 2020). Regarding the observations that androgens stimulate the production of RBCs in the bone marrow and estrogenes do for white blood cells he suggested Genital ratio (activity of androgens / activity of estrogens). In the past Ch. Duraffourd developed Genito-thyroid index $=\%$ Neutrophils $/ \%$ Lymphocytes. The normal value is $1.5-2.5$. It was defined as the relative activity of estrogens in relationship to that of thyroid. They explored also a number of biomarkers linked to upstream influences on metabolism. The essential ones are: complete blood count. Total protein, thyroid stimulating hormone (TSH), lactate dehydrogenase (LDH), creatine kinase (CK) and alkaline phosphatase bone isoenzyme (Hedayat, 2019). It means that neutrophil-lymphocyte ratio is a part of the complex response of cellular immune system to various stimuli coming from autonomic nervous system, endocrinne system (prolactin, androgens, estrogenes, cortizol, catecholamines, thyroid hormones ) and circulating mediators . NLR reflects online dynamic relationship between innate (neutrophils) and adaptive cellular immune system (Fig. 1), regarding the research of dynamic course of sepsis by Hotchkiss et al (2013). SIRS and sepsis affect significantly the physiology of hematopoiesis, erytropoiesis and differentiation of promyeloid progenitor cells under the fine tuning and neuro-imuno-humoral regulation in microenviroment of the bone marrow, defined as a stress hematopoiesis (Paulson et al, 2020). Elevated values of NLR, high activity of neutrophils and lower activity of lymphocytes (immune supression) and eosinophils are associated with higher volume and distribution widths of the blood cells size (RDW\% - red cell distribution widths, MDW\% - monocyte distribution widths \%) are now well measured by flowcytometry of the new type of hematologic cell analyzers (Crouser et al, 2017). NLR is influenced by many conditions including age, race, medications (corticoids), and chronic diseases such as ischemic heart disease, chronic heart disease, anemia, diabetes, obesity, depression disorders and cancer, i.e, those affecting the function, activity, behavior and dynamic changes in neutrophil and lymphocyte counts (Fisher et al, 2016).

\section{Normal range of physiological values of NLR in adults}

In our original paper, we assumed that pathological values of NLR are higher than 5. The priority of the article was clear, namely to postulate that the increase in NLR measures the severity of immune-inflammatory response and in general reflects the

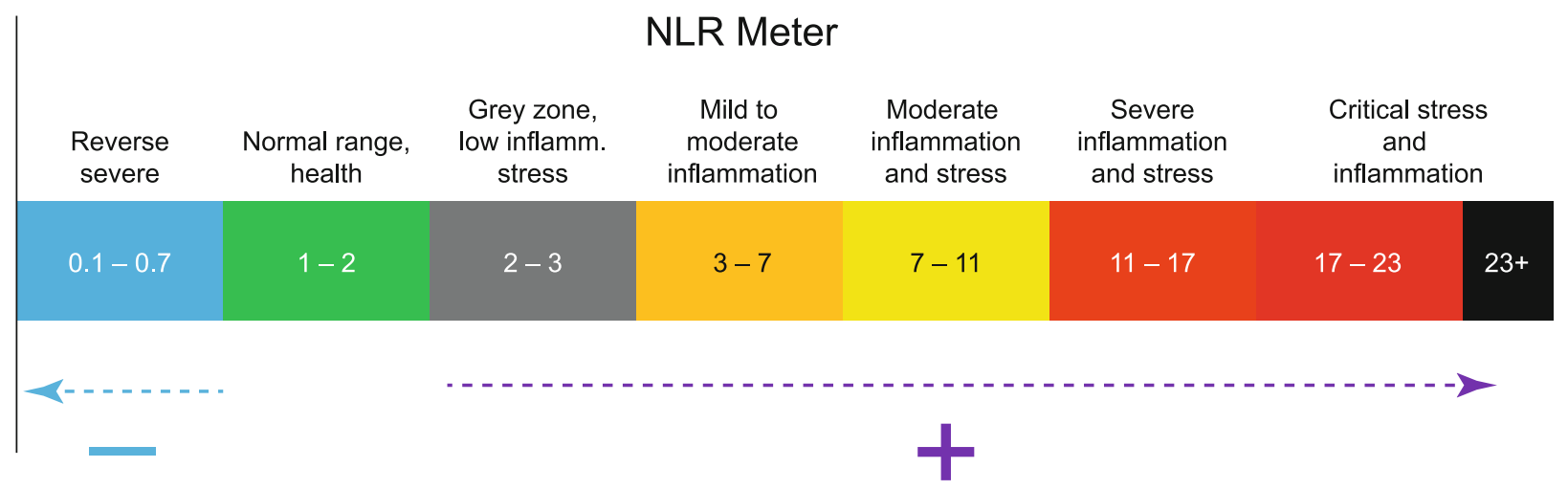

Fig. 2. NLR-meter. Neutrophil-to-lymphocyte ratio reflects the intensity of immune-inflammatory reaction and (supra-) physiological stress to insult(s) or disease. The optimal cut-off values to measure the intensity of stress and inflammatory response were refined in line with clinical trials and observations (Farkas, 2020). The cut-off values are prime numbers based on numerous clinical trials. The cut-off prime numbers on the picture above are intended merely to provide a general concept of NLR interpretation. Grey zone: latent, subclinical or low-grade inflammation/stress (NLR 2.3-3.0), mild-to-moderate inflammation (NLR 3-7), moderate and severe inflammation, systemic infection, sepsis and SIRS (NLR 7-11), severe inflammation, infection, severe sepsis and SIRS, bacteremia (NLR 11-17), critical immune-inflammatory reaction and stress with high intensity, e.g, septic shock, multiple traumas (NLR 17-23), critical systemic inflammation and supraphysiological stress, polytrauma, major surgery, terminal cancer (NLR $\geq 23+$ ). Daily follow-up of dynamic changes in NLR: upregulation/ increase is associated with worsening of the clinical course, downregulation/decrease is associated with clinical improvement and good clinical outcome. 
intensity of supraphysiological insults, severity of ongoing disease, and pathological state in general (Zahorec, 2001). Simply, high NLR values are associated with severe inflammation, stress, injury, trauma or major surgery, or cancer, and marks the worsening of the prognosis regarding morbidity or mortality (Fig. 2). But what are the normal physiological values of NLR? Several studies explored the "normal" values of NLR in an adult healthy population. The most robust is the study by Azab et al (2014) conducted on a population of 9,427 citizens of the New York state. The average value of neutrophil and lymphocyte counts were $4,300 / \mu 1$ and $2,100 / \mu 1$, respectively, while the mean value of NLR was 2.15 (reference range 1.71-2.28). The lowest average value of NLR was assessed among Afro-American individuals (NLR $=1.76$ ), the mean value of NLR among Hispanic individuals was 2.08, while NLR among Caucasian individuals was 2.24. The risk factors like smoking, obesity and diabetes mellitus were associated with mild elevation in $\operatorname{NLR}(2.21,2.34,2.44)$. Another epidemiological study analyzed hemograms from 236 young adults in Indonesia. They found the mean value of NLR to be 1.95 (reference range: $1.2-2.3$ ). All values of NLR were in range of 0.77-4.5. (Yahti et al, 2016). Another study on healthy Belgian adults were conducted by Forget et al (2017). They analyzed hemograms of 413 healthy adults and assessed the mean value of NLR to be 1.65, in range of $0.77-3.53$. Finally, an interesting study on 300 Sudanese has been conducted to measure the neutrophil and lymphocyte counts resulting in NLR in range of $0.75-1.65$ with mean value of $\mathbf{1 . 2}$. In African individuals, NLR is typically very low, namely in range of $1.0-1,2$, which is due to relative or benign neutropenia in range

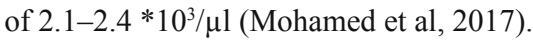

A robust epidemiological study (Lee et al, 2018) was conducted in the years 2014-2016 on a cohort of 12,160 healthy Korean citizens (6,268 men; median age $47 \mathrm{y}$ and 5,892 women; median age $46 \mathrm{y}$ ). They analyzed 12,160 blood samples that had been routinely examined for complete blood count and calculated hemogram ratios such as NLR, PLR (platelet-to-lymphocyte ratio), LMR (lymphocyte-to-monocyte ratio) and MPV (mean platelet volume, unit fl) The mean values of these parameters are as follows: $\mathbf{N L R}=\mathbf{1 . 6 5}( \pm 0.79,0.1-3.19), \mathbf{P L R}=\mathbf{1 3 2}( \pm 43.7), \mathrm{LMR}=$ $5.31( \pm 1.68)$ and $\mathbf{M P V}=\mathbf{1 0 . 0} \mathrm{fl}( \pm 0.79)$ (Tab. 2$)$. The valuable contribution of this robust trial was in the calculation of different hematological ratios (mean values and reference ranges) in a healthy adult population, which provides an important and valuable information for further research and design of clinical trials.

\section{Neutrophil-to-lymphocyte ratio and cancer}

Walsh et al (2005) were the first to apply the parameter for the prognosis of cancer patients undergoing colorectal surgery. On a cohort of 230 patients diagnosed with colorectal cancer, they assessed NLR from pre-operative complete blood counts. Pre-operative NLR greater than 5 correlated with poor prognosis, namely overall and cancer-specific survival of two years after the surgery. They concluded that pre-operative NLR represents a simple method for identifying colorectal cancer patients at higher risk and with poor prognosis (Walsh et al, 2005). The fascinating results of the retrospective study indicate that NLR as a valid immuneinflammatory parameter, predicted the clinical outcome of cancer patients and thus had a remarkable prognostic value. The relation between inflammation and prognosis of cancer expressed by NLR has enhanced the epidemiologic research of NLR in various solid tumors in the next years of 2005-2020 (Ohno et al, 2010, 2012, Pichler et al, 2012, Guthrie et al, 2013, Guthrie 2016, Bowen et al, 2017, Howard et al, 2019). NLR is a very sensitive marker of acute, subacute and/or chronic inflammation in association with infectious diseases (PAMP), non-infectious diseases (DAMP) and diseases with mixed etiology (PAMP + DAMP) (Fig. 3, Tab. 3). There is a growing body of evidence of parallels between cancer and infectious diseases with characteristic changes in the blood and hemograms (Hotchkiss Moldawer, 2014), clinically and laboratory manifested as SIRS (Boshier et al, 2016). The values of NLR for low-grade inflammation, subclinical or latent inflammation, and stress of low intensity are associated with very low values in the grey zone (NLR in range of 2.3-2.9, or in range of 2.5-3.0). Such low values of NLR are typical for cancer of different solid tumors (Bowen et al, 2017; Howard et al, 2019). The role of local and systemic inflammation in the cancer disease was well recognized a decade of years ago; several terms have been used to describe this syndrome, such as cancer-associated systemic inflammation, malignant SIRS, or cancer-induced inflammatory response (McMillan, 2003, Colotta 2009, Grivennikov, 2009, Mantovani et al, 2009, Hannahan and Weinberg, 2011). Sepsis, SIRS and cancer have many common features such as immune activation, acute phase response, anemia, systemic inflammation, hypercoagulation and elevation in NLR (Arigami, 2016, Ishizuka et al, 2014, Sun X 2016). At present, NLR is broadly used and accepted for the purpose of evaluating ongoing systemic inflammation during cancer development, severity stratification, and prognosis of cancer disease (Ohno et al, 2010, 2012, Pichler et al, 2012, Guthrie et al, 2013, Guthrie, 2016, Arigami et al, 2016, Sun X et al, 2016, Bowen et al, 2017, Howard et al, 2019, Cupp et al, 2020).

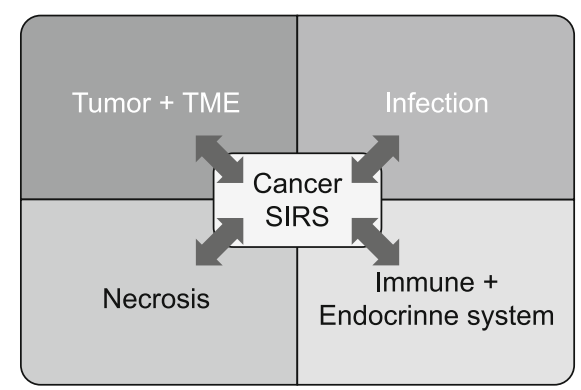

Fig. 3. Cancer-associated systemic inflammation or "cancer SIRS" induced by immune activation and inflammation due to the tumor growth and tumor microenvironment; necrosis inside the tumor, infected necrosis, co-infection, progression of cancer. Even anticancer (oncological) therapy may contribute to CASI worsening. NLR may serve as the key sensitive parameter of CASI or "cancer SIRS". NLR per se is an immune-cell hallmark of SIRS (non-infectious, infectious and mixed DAMP+PAMP). DAMP - damage-associated molecular pattern, PAMP - pathology-associated molecular pattern. 
Tab. 3. Common parallels between cancer, SIRS, and sepsis in routine laboratory parameters, and hemogram(s).

\begin{tabular}{|c|c|}
\hline CANCER - laboratory parameters and complete blood count & $\begin{array}{l}\text { Infectious disease, bacteremia and sepsis, SIRS complete blood count, } \\
\text { biochemical parameters: }\end{array}$ \\
\hline ANEMIA of cancer hbg < $120 \mathrm{~g} / \mathrm{l}$ (Szkandera 2014, Gorphe 2017) & Anemia of inflammation, $\mathrm{hbg}<120 \mathrm{~g} / \mathrm{l}$ \\
\hline Increase in ESR, RDW\%, MPV, CD163 elevated & Increase in ESR, RDW\%, MDW\%, MPV, CD163 \\
\hline Thrombocytosis $\geq 300.10^{9} / \mu 1$, higher values of PLR $\geq 200$, or $\geq 300$ & $\begin{array}{l}\text { Thrombocytopenia }<150-100.10^{9} / \mu 1, \\
\text { or thrombocytosis } \geq 300.10^{9} / \mu 1\end{array}$ \\
\hline $\begin{array}{l}\text { Acute-phase proteins positive - CRP, fibrinogen, hyperfibrinogenemia } \\
\geq 3.8-4.0 \mathrm{~g} / \mathrm{l} \text {, ferritin }\end{array}$ & $\begin{array}{l}\text { Acute phase proteins-CRP } \geq 40-150 \mathrm{mg} / 1 \text {, fibrinogen } \geq 4,0 \mathrm{~g} / 1 \text {, ferritin, } \\
\text { serum amyloid A, }\end{array}$ \\
\hline $\begin{array}{l}\text { Acute-phase proteins negative-transferrin, hypoalbuminemia, low } \\
\text { cholesterol (HDL-cholesterol) }\end{array}$ & $\begin{array}{l}\text { Acute phase proteins negative-transferrin, hypoalbuminemia, low } \\
\text { cholesterol (low HDL-cholesterol) }\end{array}$ \\
\hline $\begin{array}{l}\text { Mild increase of NLR }(2.5-5.0) \text {, PLR }(\geq 200-300,) \text { lymphopenia } \\
(<21 \%) \text {, monocytosis } \geq 10 \% \text { of WBC }\end{array}$ & $\begin{array}{l}\text { Marked increase in NLR (5-31), neutrophilia, lymphopenia, } \\
\text { eosinopenia, monocytopenia }\end{array}$ \\
\hline
\end{tabular}

Hyperglycemia, hyperlactatemia, high/low uric acid, low bilirubin, increase in activity of LDH

ESR - erythrocyte sedimentation rate, $\mathrm{RDW}$ - red distribution width, MPV - mean platelet volume, MDW\% - monocyte distribution width in \%, CRP - C-reactive protein, hbg - hemoglobin, PLR - platelet to lymphocyte ratio, SIRS - systemic inflammatory response syndrome,

Several meta-analyses have explored the prognostic value of NLR in various solid tumors. The best studies were done in gastrointestinal cancers. Bowen et al (2017) analyzed 144 studies comprising 45,905 patients. The mean, median, and mode cut-off values for NLR relative to overall survival from multivariate models were 3.4, 3.0 and 5.0 (IQR 2.5-5.0), respectively. The association between NLR value, OS and disease-free survival was observed in all subgroups based on tumor site, stage, and region. Evidence suggests that NLR greater than the cut-off value (median NLR 2 3.0) IQR 2.5-5.0 reduces OS independently of gastrointestinal cancer type, or stage of cancer (Bowen et al, 2017). Howard et al (2019) explored group-specific cut-off values of neutrophil-tolymphocyte ratio in different types of cancer for precise clinical validation as a tool for risk stratification. The eight cancer types including CRC were selected from 228 published studies and over 75,000 patients. A total of 5,363 patients were included in the final analysis where 1,024 were out of colorectal cancer. They found out the optimal cut-off value of NLR to be $<3.22$ for overall survival. In each type of cancer, the overall survival and disease-free survival are significantly better in patients with NLR lower than median. Patients with NLR higher than median have poor clinical outcome with shorter overall survival (Howard et al, 2019).

Majority of meta-analyses have assessed the cut-off value of NLR to be above 3.0 (IQR 2.5-5.0) as a valid reliable prognostic index for the purpose of evaluating the prognosis of various solid tumors. Cancer is the leading cause of disease worldwide. There is an increasing body of evidence that cancer-associated inflammation is the key determinant of outcome in patients with cancer (McMillan 2003, Grivenikov 2009, Mantovani 2009, Guthrie et al, 2013, Strumpfa et al, 2017, Howard et al, 2019). Cancer induces a systemic inflammatory response syndrome (cancer-induced SIRS) or cancer-associated systemic inflammation (CASI) manifesting with changes in counts of leukocyte populations (Fig. 3), concentrations of acute phase proteins, coagulation factors, hemoglobin and albumin (Mantovani et al, 2008, Boshier et al, 2016). Various markers of inflammation have been examined over the past two decades in an attempt to refine stratification of patients to treat- ment and predict their survival (Guthrie et al, 2013). It has been increasingly apparent that cancer-associated systemic inflammation is the key determinant of disease progression and survival in most cancers. At present, neutrophil-to-lymphocyte ratio has become a routinely available marker of systemic inflammatory response. To date, more than 140 studies have examined the clinical utility of NLR to predict outcomes in a variety of cancers (Paramanathan et al, 2014, Howard et al, 2019, Cupp et al, 2020). Many systematic reviews have examined and commented on the clinical utility of NLR, as follows:

- NLR is a valid and reliable marker of systemic inflammation including CASI and SIRS (Boshier et al, 2016, Fisher et al, 2016, Howard et al, 2019).

- NLR is widely available, physician and patient-friendly, and economically feasible.

- NLR is an independent prognostic parameter in unselected cohorts of studies exploring the survival after oncological treatment in various types of cancer (Guthrie et al, 2013, Howard et al, 2019). - NLR correlates with more advanced (TNM classification) and aggressive disease (grade of cancer), evidenced by size (volume) of tumor, increased tumor stage, nodal stage, lymphatic invasion and metastatic lesions (together with an increase in platelet count and fibrinogen concentration) (Li et al, 2014, Arigami et al, 2016, Palaj et al, 2018).

- NLR has an independent prognostic role regarding overall, cancer-free and cancer-specific survival (Howard et al, 2019, Cupp et al, 2020).

- NLR is useful for monitoring oncological therapy regarding chemotherapy, radiotherapy, patients with inoperable cancer on palliative therapy (Ferrucci, 2015, Capone et al, 2018).

- NLR may be used for the purpose of monitoring immune and biological modes of therapy (Shindo et al, 2019, Ishihara et al, 2021).

- NLR reflects the intensity of immune-inflammatory response and stress reaction to cancer.

- NLR is a sensitive marker of cancer-associated systemic inflammation together with other inflammatory markers such as CRP, 
Tab. 4. The neutrophil-to-lymphocyte ratio utility for laboratory screening and laboratory diagnostics, risk stratification, prognosis and clinical outcome: Full citation of authors and titles on request.

\begin{tabular}{|c|c|c|}
\hline Diagnosis, nosological entity & Cut-off values, IQR, range & First Author, year of publication \\
\hline $\begin{array}{l}\text { Infection, bacteremia, bacterial } \\
\text { pneumonia, viral infection, } \\
\text { COVID-19 pneumonia }\end{array}$ & $\begin{array}{l}\text { NLR } \geq 3-7 \text { for bacterial infection } \\
\text { NLR } \geq 10-11 \text { for bacteremia, sepsis } \\
\text { NLR } \geq 7-11 \text { for bacter. pneumonia } \\
\text { NLR } \geq 3-7 \text { for mild COVID-19 } \\
\text { NLR } \geq 7-11 \text { for severe COVID pneumonia }\end{array}$ & $\begin{array}{l}\text { Wyllie 2005, Chalupa 2011, Holub 2012, de Jager 2010, 2012, Loonen 2014, } \\
\text { Sen 2016, Russel 2019, Marik 2020, Lian 2020, Liu 2020, Ye 2020, Fu 2020, } \\
\text { Ma 2020, Generali 2021, Imran 2021, Nestor 2021, Sciacchitano } 2021\end{array}$ \\
\hline Acute pancreatitis & $\begin{array}{l}\text { Mild AP } \\
\text { NLR } \geq 4-7.0 \\
\text { Moderate AP, } \\
\text { NLR } \geq 7-11 \\
\text { Severe AP, } \\
\text { NLR } \geq 11-17\end{array}$ & $\begin{array}{l}\text { Azab 2011, Suppiah 2013, Kokulu 2018, Cho 2018, Yu 2019, Kong 2020, } \\
\text { Ekin 2020, Mubder } 2020\end{array}$ \\
\hline Acute appendicitis & $\begin{array}{l}\text { Catarrhal AA NLR } \geq 3.1-4.0 \\
\text { Seropurulent AA, NLR } \geq 3.5-5.0 \\
\text { Gangrenous AA, NLR } \geq 5.5-7.0\end{array}$ & Ishizuka 2012, Kahramanca 2014, Toktas 2017, Goodman 1995, Celik 2019 \\
\hline $\begin{array}{l}\text { Sepsis and septic shock, SIRS, } \\
\text { critical illness }\end{array}$ & $\begin{array}{l}\text { Sepsis NLR } \geq 7-17, \text { IQR } 3-23 \\
\text { Septic shock NLR } \geq \mathbf{1 1 - 1 7} \\
\text { In neutropenia: NLR }<0.7-0.5-0.2 \\
\text { SIRS non-infectious NLR } \geq \mathbf{3 - 1 3}\end{array}$ & $\begin{array}{l}\text { Salciccioli 2015, Riché 2015, Gurol 2015, Gucyetmez 2016, Liu 2016, Hwang } \\
\text { 2017, Arif 2017, Yoldas 2018, Ljungstrom 2017, Sari 2019, Farkas 2020, Marik } \\
\text { 2020, Zhou 2021, Zhong 2021 }\end{array}$ \\
\hline $\begin{array}{l}\text { Acute coronary syndrome } \\
\text { Acute myocardial infarction } \\
\text { NSTEMI, STEMI, prognosis }\end{array}$ & $\begin{array}{l}\text { NLR } \geq 3.34-4.0 \text { (NSTEMI) } \\
\text { NLR } \geq 3.8-5.5 \text { (STEMI) } \\
\text { NLR } \geq 5.7-6.3 \text { (worse prognosis) }\end{array}$ & $\begin{array}{l}\text { Tamhane 2008, Akpek 2012, Arbel 2012, Bhat 2013, Pan 2014, Kurtul 2015, } \\
\text { Chen 2018, Park } 2018\end{array}$ \\
\hline $\begin{array}{l}\text { Acute stroke, ischemic, } \\
\text { hemorrhagic }\end{array}$ & $\begin{array}{l}\text { NLR } \geq 4.1-5.0 \\
\text { NLR } \geq 4.6-5.4 \\
\text { NLR } \geq \mathbf{5 . 7 - 8 . 5} \text { (worse prognosis) }\end{array}$ & $\begin{array}{l}\text { Tokgoz 2013, Celikbilek 2014, Erturk 2014, Brooks 2015, Lattanzi 2016, } \\
\text { 2020, Giede-Jeppe 2017, Wang 2018, Ozgen et al } 2020\end{array}$ \\
\hline Head and neck cancer, SCCM & $\begin{array}{l}N L R \geq 2.6-3.0 \\
N L R \geq 4.0-5.0\end{array}$ & $\begin{array}{l}\text { Millrud R.C 2012, Young 2014, Panje 2017, Gorphe 2018, Sato 2017, } \\
\text { Ferrandino 2016, 2020, Andersson } 2019\end{array}$ \\
\hline $\begin{array}{l}\text { Urology, renal cancer, } \\
\text { prostate cancer }\end{array}$ & $\begin{array}{l}\text { NLR } \geq 2.7-3.0 \\
N L R \geq 3.3-3.6\end{array}$ & $\begin{array}{l}\text { Ohno 2010,2012, Pichler 2013, Kuzman 2017, Hu 2015, Tan 2017, Luo } \\
2015,2018\end{array}$ \\
\hline Esophageal and gastric cancers & $\begin{array}{l}\text { NLR } \geq \mathbf{2 . 6}-\mathbf{4 . 0} \\
\text { NLR } \geq \mathbf{4 . 0}-\mathbf{5 . 0} \\
\text { NLR } \geq \mathbf{5 . 0}\end{array}$ & $\begin{array}{l}\text { Rashid 2010, Yamanaka 2007, Jung 2011, Aliustaoglu 2010, Shimada 2010, } \\
\text { Miyata 2011, Sato 2012, Jeong 2012, Lee 2013, Kim 2015, Ishizuka 2014, } \\
\text { Sun X 2016, Strumfa 2017, Yao } 2018\end{array}$ \\
\hline $\begin{array}{l}\text { Cancer of pancreas, pancreatic } \\
\text { ductal adenocarcinoma }\end{array}$ & $\begin{array}{l}\mathbf{N L R} \geq \mathbf{4 . 0} \\
\mathbf{N L R} \geq \mathbf{5 . 0} \\
\mathrm{NLR} \geq 3.6-5.1\end{array}$ & $\begin{array}{l}\text { Smith R 2009, Bhatti 2010, An 2010, Garcea 2011, Luo 2015, Yang 2015, } \\
\text { Cheng 2015, Lee 2018, Zhou 2018, Howard 2019, Iwai } 2020\end{array}$ \\
\hline $\begin{array}{l}\text { Liver cancer HCC, hepatic } \\
\text { metastasis }\end{array}$ & $\begin{array}{l}\text { NLR } \geq 4.0 \\
N L R \geq 5.0\end{array}$ & $\begin{array}{l}\text { Gomez 2008, Hakazun 2008, Neal 2011, Kinoshita 2012, Motomura 2013, } \\
\text { Aino 2013, Qi 2016, Wang } 2020\end{array}$ \\
\hline Colorectal cancer & $\begin{array}{l}\text { NLR } \geq \mathbf{2 . 5}-\mathbf{3 . 0 .} \text { IQR } 2.3-5.5 \\
\text { NLR } \geq 3.1-4.0 \\
\text { NLR } \geq \mathbf{4 . 0}-\mathbf{5 . 0}\end{array}$ & $\begin{array}{l}\text { Walsh 2005, Cook 2007, Chua 2011, Kantola 2012, Jankova 2013, } \\
\text { Templeton 2014, Ozgehan 2014, Malietzis 2014, Seong 2015, Mei 2017, } \\
\text { Benlice 2019, Yoshida } 2020\end{array}$ \\
\hline $\begin{array}{l}\text { Gynecology, cancer of Ovarium, } \\
\text { uterus cervix and, vulva }\end{array}$ & $\begin{array}{l}\text { NLR } \geq 2.6-3.3 . \text { NLR } 2.5-3.9 \\
\text { NLR } \geq 2.3-5.26 \\
\text { NLR } \geq 2.6-4.0\end{array}$ & $\begin{array}{l}\text { Cho 2009, Li 2015, Wu 2017, Prodromidou } 2017 \text { ethier 2017, Zhoua 2017, } \\
\text { Zhao 2018, Ding 2019, Lee } 2021\end{array}$ \\
\hline Sarcoma, soft tissue sarcoma & $\begin{array}{l}N L R \geq 5.0 \\
N L R \geq 4.0\end{array}$ & Idowu 2012, Szkandera 2015, Liu G 2018 \\
\hline Breast cancer & $\begin{array}{l}\text { NLR } \geq 3.0-3.3 \\
N L R \geq 2.57-4.0\end{array}$ & Azab 2013, Dirican 2015, Liu 2016 Ethier J-L 2017, Yao 2014 \\
\hline $\begin{array}{l}\text { Skin cancer, malignant } \\
\text { melanoma }\end{array}$ & $\begin{array}{l}\mathrm{NLR} \geq 4.0 \\
\mathrm{NLR} \geq 5.0\end{array}$ & Ferruci 2015, Zaragoza 2016, Ding 2018, Cohen et al 2020, Fattore 2021 \\
\hline $\begin{array}{l}\text { Lung cancer, pulmonary } \\
\text { non-small and adenocarcinoma }\end{array}$ & $\begin{array}{l}\text { NLR } \geq 2.63-3.25 \\
\text { NLR } \geq 4.74-5.0\end{array}$ & Sarraf 2009, Sakai 2011, Tomita 2011, Kao 2010, Yao 2012, Ishihara 2021 \\
\hline $\begin{array}{l}\text { Orthopedics, poly trauma. } \\
\text { burn injury }\end{array}$ & $\begin{array}{l}\text { NLR } \geq 3.3-4.0 \\
N L R \geq 4.0-5.0 \\
N L R \geq 3.6-4.0 \\
N L R \geq 3.5-5.5\end{array}$ & $\begin{array}{l}\text { Hefernnan 2012, Forget 2015, Emektar 2017, Fisher 2016, Angulo 2020, } \\
\text { Temiz 2019, Bac 2020, Wang 2020, Qiu } 2021\end{array}$ \\
\hline $\begin{array}{l}\text { Ulcer colitis, inflammatory } \\
\text { bowel disease (IBD) }\end{array}$ & $\begin{array}{l}\text { NLR } \geq 3.3 \\
N L R \geq 4.1-5.0\end{array}$ & Celikbilek 2013, Acarturk 2015, Gao 2015, Kang 2017, Argeny 2018 \\
\hline $\begin{array}{l}\text { Psychiatry bipolar disorders, } \\
\text { depression, schizophrenia }\end{array}$ & $\begin{array}{l}N L R \geq 2.3-4.0 \\
N L R \geq 2.4-3.0 \\
N L R \geq 2.5-4.0\end{array}$ & $\begin{array}{l}\text { Aydin 2016, Demir 2015, Demircan 2016, Kalelioglu 2015, 2019, } \\
\text { Karamustafalioglu 2019, Kulaksizoglu 2019, Ozdin 2020, Mazza } 2018\end{array}$ \\
\hline $\begin{array}{l}\text { Urgent medicine, } \\
\text { emergency }\end{array}$ & $\begin{array}{l}\text { NLR } \geq 10 \\
\text { NLR } \geq 12\end{array}$ & $\begin{array}{l}\text { Wyllie 2004, de Jager 2010, 2012, Loonen 2014, Vallejo 2017, Kim Park } \\
\text { 2019, Westerdijk } 2019\end{array}$ \\
\hline Veterinary medicine & NLR $\geq 11$ infection in dogs & Pierini et al 2019 \\
\hline
\end{tabular}


albumin, platelet count, fibrinogen (Guthrie et al, 2013, Seong, 2015, Arigami et al, 2016, Palaj et al, 2018).

- NLR may be used for the purpose of stratification of high-risk patients and further cancer therapy (Pinato et al, 2014),

- NLR may identify novel treatment strategies for patients with cancer (Pinato et al, 2014, Chen et al, 2017, Shindo et al, 2019, Ishihara et al, 2021).

\section{NLR in sepsis, systemic inflammation, and SIRS}

In 2001, we analyzed the dynamic relation between neutrophil and lymphocyte populations as a number, and/or as a ratio, which can be easily and automatically calculated by dividing absolute/or relative neutrophil counts by absolute/or relative lymphocyte counts. The main issue was in the application of NLR in patients with sepsis, SIRS or severe bacterial infection. W. Aird (2003) pointed out that the hematologic system has the role of being the primary organ involved in the pathogenesis of sepsis. All blood cells are activated during systemic infection and sepsis, which brings about significant changes in its counts, function, receptor expression and secretion of various signal molecules and humoral substances. Complete blood count may provide a wealth of valuable information which can be read from the hemogram. NLR is such a parameter. The sensitivity of NLR in the diagnosis of bacteremia, infection and sepsis was validated in numerous studies (de Jager, 2010, Salciccioli et al, 2015, Riché et al, 2015, Liu et al, 2016, Hwang et al, 2017, Ljungstrom et al, 2017, Farkas, 2020, Marik et al, 2020, Ham et al, 2020). NLR has been used as a valuable prognostic tool in septic patients. Akilli et al (2014) conducted a prospective study of critically ill patients who were admitted at emergency department (ED) and later required ICU care. The patients with high NLR measured at ED had significantly higher in-hospital and 6-month mortality rates. A robust retrospective study has been conducted on a large cohort of critically ill patients by Salciccioli et al (2015). They assessed, using multivariable regression, the relationship between initial NLR and outcomes in cohorts of patients with and without sepsis. Initial NLR was recorded on the day of ICU admission. A cohort of 5,056 adult ICU patients was divided into four subgroups according to quartiles of NLR: $<4.99,5-8.9,8.9-16.2$ and NLR $\geq$ 16.21. The clinical, laboratory and outcome data were analyzed across quartiles of NLR. They observed a significant association between increased NLR and crude 28-day mortality, which was $13 \%$ in first quartile, $20 \%$ in third quartile and $28 \%$ in fourth quartile; $\mathrm{p}<0.001$. However, there was no association between NLR and mortality in the sepsis subgroup (1,832 patients) (Salciccioli et al, 2015). Riché et al (2015) analyzed an association between NLR and risk of death in a cohort of 130 patients with septic shock. The medians of NLR in survivors and non-survivors were 12.5 and 6.2 , respectively $(p<0.001)$. The early death of septic shock patients was associated with insufficient or abnormal immune response, namely with neutropenia. The late death after 5 days depends on the course of NLR, increase in NLR during the days following the ICU admission, which were significantly associated with death. It is of importance that not only the initial value of NLR is crucial, but also the dynamic changes in NLR are an objective index of the severity of illness (Riché et al, 2015). Hwang et al (2017) explored the prognostic value of the initial NLR in a cohort of 1,395 septic patients. They followed up 28day hospital mortality according to the initial value of NLR. The whole group was divided into five subgroups across the quintiles of NLR. Their results of NLR medians are as follows: 0.2 (IQR $0.1-0.7$ ) in quintile 1 , NLR 8.6 (IQR 7.1-9.9) in quintile 3 and $31(24.6-46.8)$ in quintile 5. The highest mortality was recorded in quintiles 1 and 5 (24.4\% and $16.6 \%$, respectively). The comparison of initial NLR across quintiles confirmed that sepsis is a heterogenous clinical syndrome with high variability of total leukocyte counts (leukopenia vs leukocytosis) while the highly dynamic course of neutrophil and lymphocyte counts results in changes in NLR. They pointed out that not only the high values

Tab. 5. NLR as part of the panel of inflammatory biomarkers for cancer screening, stratification and prognosis of clinical outcome.

\begin{tabular}{|c|c|c|}
\hline $\begin{array}{l}\text { Panel of inflammatory markers } \\
\text { for cancer }\end{array}$ & $\begin{array}{l}\text { Hematologic and biochemical parameters } \\
\text { of inflammation }\end{array}$ & Authors, year of publication \\
\hline First line & $\begin{array}{l}\text { NLR, neutrophils count, } \mathrm{Hbg} \\
\text { trombocytes count, Albumin, CRP, } \\
\text { fibrinogen }\end{array}$ & $\begin{array}{l}\text { Seong 2015, Kang 2017, Mohamed 2013, Sun 2016, Ishizuka } \\
\text { 2014, Zheng 2009, Boshier 2016, Arigami 2016, Kanda 2017, } \\
\text { Zahorec } 2021\end{array}$ \\
\hline Second line & $\begin{array}{l}\text { PLR, RDW \%, MPV, CRP/Alb, ESR, } \\
\text { lactate, LDH, uric acid, bilirubin, } \\
\Delta \text { NLR, dNLR, lymphocytes count } \\
\end{array}$ & $\begin{array}{l}\text { Ishizuka 2014, Proctor 2012, Pinato 2014, Seong 2015, Kang } \\
2017\end{array}$ \\
\hline $\begin{array}{l}\text { Inflammation-based score for } \\
\text { cancer-associated inflammation and } \\
\text { nutrition-based score }\end{array}$ & $\begin{array}{l}\text { PNI, PIS, mGPS, GPS, SII, Inflamatory } \\
\text { based score, Canton score (PNI + NLR } \\
+ \text { PLT count) }\end{array}$ & $\begin{array}{l}\text { Onodera 1989, McMillan 2003, Proctor 2012, Chen 2017, Guth- } \\
\text { rie 2013, Pinato 2014, Seong 2015, Sun } 2015\end{array}$ \\
\hline $\begin{array}{l}\text { Bayesian method; combination of } \\
\text { clinical and pathological parameters }\end{array}$ & $\begin{array}{l}\text { Specific oncomarkers, TNM classification, } \\
\text { pT, pN, N1, N2, M0 M1, grade 1, vs grade 3, } \\
\text { tumor size (volume), lymphatic and } \\
\text { angio invasion, microsatelite instability }\end{array}$ & $\begin{array}{l}\text { Akgul 2017, Lou 2017, Kang 2017, Chen 2017, Shi et al 2019, } \\
\text { Shindo et al } 2019\end{array}$ \\
\hline
\end{tabular}

LDH - lactate dehydrogenase, PNI - prognostic nutritional index (Onodera 1989), PIS - prognostic inflammatory score (Seong 2015), GPS - Glasgow prognostic score (McMillan and Proctor 2003, 2007, 2010), mGPS +NLR (Guthrie et al, 2013), Inflammation-based score - Pinato 2014, Mohamed 2013, SII - systemic immune-inflammation index (Chen et al, 2017) 
of NLR, but even the very low values below 0.7 are associated with significant morbidity and mortality (Hwang et al, 2017). Many trials have explored the position of NLR as an inflammation biomarker in association with bacteremia, bacterial infection and sepsis, as compared with procalcitonin, C-reactive protein, interleukin-6 and lactate. C. de Jager et al (2010) demonstrated the priority of NLCR and lymphocyte counts over CRP and total white blood cell count for the diagnosis of bacteremia and systemic infection on a cohort of 184 patients in the setting of emergency department, 92 patients with positive hemocultures and 92 patients with negative hemocultures. They observed a significant difference in NLCR between the study cohort (mean NLCR 20.9) and an age-matched control group (NLCR 13.2; $<<0.001$ ). In the emergency care setting, both NLCR and significant lymphocytopenia were better predictors of bacteremia than the routine parameters such as CRP level and total WBC count. Gurol et al (2015) assessed procalcitonin as a reference marker and predictor of sepsis and septic shock and compared it with NLR, CRP and total leukocyte counts using ROC analysis. They concluded that NLR was a valid indicator of sepsis when NLR was equal to or higher than 5 . They found a correlation between serum procalcitonin concentration and NLR values in critically ill patients with sepsis; PCT values from 2-10 ng/ml and NLR in range of 11-15; PCT values for septic shock above $10 \mathrm{ng} / \mathrm{ml}$ and NLR values above 15-17. Significantly higher values of NLR. CRP, PCT and IL-6 were observed in ICU patients with sepsis and septic shock. Gucyetmez et al (2015) conducted a retrospective study in 1,257 ICU patients to distinguish sepsis form non-infectious SIRS by means of hemogram and C-reactive protein levels while 816 patients $(65 \%)$ were categorized as having non-sepsis SIRS and 441 patients (35\%) had sepsis. They assessed the cut-off values for discriminating sepsis to be as follows: NLR $\geq 14.2, \mathrm{CRP} \geq 40$ $\mathrm{mg} / \mathrm{l}$, lymphopenia $<450 / \mu 1$, platelet count $<150 * 10^{3} / \mu 1$, SOFA score $\geq 4$ points, and APACHE II $\geq 13 \mathrm{p}$. When using multivariate analysis, the likelihood of sepsis increased with SOFA score, platelet count, lymphocytopenia and CRP levels. NLR value and eosinophil count were not significant for distinguishing sepsis from SIRS (Gucyetmez et al, 2015).
Ljungstrom et al (2017) performed a prospective study on 1,572 adults admitted to the emergency department with a suspected sepsis syndrome. NLR was superior to C-reactive protein but inferior to procalcitonin in terms of cut-off values. In a retrospective study, sepsis patients (591) were divided according to the presence of septic shock (228 patients) and subgroups were formed according to mortality, namely subgroups of survivors (117 patients, $19.8 \%$ ) and non-survivors (111 patients, $18.8 \%$ ). They followed up the patients for APACHE II and SOFA score, NLR and C-reactive protein serum levels on days 1, 3 and on last day of stay at ICU. The median values of initial NLR in septic shock patients were as follows: 13.48, 10.97 and 8.19, respectively. The NLR was a reliable and valid parameter for monitoring the response to antibiotic and intensive therapy. The survivors and responders to therapy had a significant decline in NLR values on day 3. The opposite was true for unresponsive patients whose NLR was increased. In cases of NLR being $\geq 15$ on day 3, the mortality odds ratio was 6.96 . NLR can predict mortality and therapy responsiveness in ICU patients with sepsis and septic shock. The dynamic changes in NLR in the first 3-5 days are crucial for the prognosis and outcome in ICU patients (Sari et al, 2019). A recent research on biomarkers of sepsis confirmed that reliable and valid biomarkers used for the diagnosis, monitoring and stratification of sepsis, systemic infection and SIRS include IL-6, NLR, procalcitonin, C-reactive protein and lactate (Ljungstrom et al, 2017, Marik et al, 2020).

The level of stress, major injury and/or inflammation and severity of clinical state are easily derived from increasing values of NLR (Fig. 1 and 2) (Záhorec, 2017). Amelioration of the course of sepsis and SIRS, improvement in prognosis and lowered risk of morbidity/mortality are associated with the decline in NLR (Farkas, 2020, Zahorec, 2017). NLR is helpful in differentiating a more severe disease from a milder one. NLR is a very rapid and valid immunologic marker of ongoing inflammation, infection, tissue injury, stress response to a disease, and organ dysfunction, as well as reflects the severity of the disease per se.

Tab. 6. NLR as a part of sepsis biomarkers for laboratory screening of infection, bacteremia, systemic inflammation, sepsis and SIRS in critical ill patients.

\begin{tabular}{|c|c|c|}
\hline Panel of biomarkers of sepsis & $\begin{array}{l}\text { Panel of hematological and biochemical } \\
\text { parameters for inflammation and infection }\end{array}$ & Authors, year of publication \\
\hline First line & $\begin{array}{l}\text { PCT, CRP, IL-6, NLR, } \Delta \text { NLR, Hbg, Alb, } \\
\text { Fbg, lymphocytes }\end{array}$ & $\begin{array}{l}\text { Ljungstrom 2017, Hwang 2017, Jansma 2013, Salciccioli 2015, } \\
\text { Riché 2015, Yoldas 2018, Sari 2019, Sen 2020, Zhou } 2020\end{array}$ \\
\hline Second line & $\begin{array}{l}\text { Presepsin (sCD14), nCD64, RDW\%, } \\
\text { MDW\%, sTREM-1, ferritin, eosinopenia, } \\
\text { D-dimer, Lactate }\end{array}$ & $\begin{array}{l}\text { Gucyetmez 2016, Liu 2017, Naess 2017, Sankar Webster } \\
\text { 2015, Crouser 2017, 2019. Marik } 2020\end{array}$ \\
\hline $\begin{array}{l}\text { Ratios used for SIRS, infection and } \\
\text { sepsis detection /diagnosis }\end{array}$ & $\begin{array}{l}\text { CRP/Alb, PCT/ALB, CLR, PNI, PLR, } \\
\text { MLR, RDW\%, ferritin/transferin }\end{array}$ & Bateman 2017, Iskandar 2016, Arif 2017, Neary C 2020 \\
\hline $\begin{array}{l}\text { Bayesian methods for SIRS, infection } \\
\text { and sepsis, combination of clinical } \\
\text { sign and symptoms + biomarkers + age }\end{array}$ & $\begin{array}{l}6 \text { SIRS criteria: altered mental status, tachypnoe, } \\
\text { dyspnoe, hypoxemia, fever, tachycardia, } \\
\text { hypotension, + oliguria, + acidosis }\end{array}$ & $\begin{array}{l}\text { Elebute Stoner 1983, Bone 1992, Fisher et al 2016, } \\
\text { Orphanu 2020, Marik } 2020\end{array}$ \\
\hline
\end{tabular}


Tab. 7. Procedural issues and suggestions for routine clinical use.

\begin{tabular}{|c|c|}
\hline Procedural issues of NLR Technological items & Suggestion for clinical use, Utility \\
\hline $\begin{array}{l}\text { Automatic calculation of NLR by means of hemogram analyzer, } \\
\text { blood counter }\end{array}$ & NLR as a standard parameter of hemogram \\
\hline $\begin{array}{l}\text { Automatic results of hemogram, complete blood count (CBC) and } \\
\text { differential }\end{array}$ & $\begin{array}{l}\text { NLR }=\text { calculated as ratio between } \\
\text { absolute neutrophil count /absolute lymphocyte count }\end{array}$ \\
\hline $\begin{array}{l}\text { Serial investigation: Every } 6-12 \text { hours in acute disease, then on } \\
\text { a daily routine basis-morning }\end{array}$ & $\begin{array}{l}\text { Follow up the dynamic changes, delta } \Delta \mathrm{NLR}=\mathrm{NLR}_{2}-\mathrm{NLR}_{1} \text {, or derivate } \\
\mathrm{NLR}=\mathrm{NLR} / \mathrm{NLR}_{0}\end{array}$ \\
\hline $\begin{array}{l}\text { Quality of hemogram, right interpretation with clinical context, } \\
\text { careful evaluation }\end{array}$ & $\begin{array}{l}\text { Screening and warning in emergency, acute on chronic disease, } \\
\text { subclinical inflammation }\end{array}$ \\
\hline $\begin{array}{l}\text { Compare with other laboratory parameters and clinical signs and } \\
\text { symptoms (Bayesian method) }\end{array}$ & $\begin{array}{l}\text { Monitoring of the course of immune-inflammation response, early } \\
\text { diagnosis }\end{array}$ \\
\hline $\begin{array}{l}\text { Use different panels of markers according the primary diagnosis to } \\
\text { follow-up the course }\end{array}$ & $\begin{array}{l}\text { Stratification of syndrome or disease, Combine NLR + hbg, fbg, Alb, } \\
\text { plts, CRP, PLR, PNI, IL-6, PCT }\end{array}$ \\
\hline $\begin{array}{l}\text { Hospital morbidity/mortality, long-term } 2-5 \mathrm{y} \text {. mortality, use with } \\
\text { other signs and parameters }\end{array}$ & Prognosis and outcome, prediction \\
\hline
\end{tabular}

Tab. 8. The utility of NLR in clinical medicine, early diagnosis, decision-making process, evaluation of severity, stratification, monitoring the therapeutic effectiveness, prediction and prognosis.

\begin{tabular}{ll}
\hline $\begin{array}{l}\text { Properties and quality of NLR as an index } \\
\text { NLR highly sensitive parameter of inflammation, stress for evaluation } \\
\text { the course of disease }\end{array}$ & $\begin{array}{l}\text { Utility in clinical disciplines } \\
\text { veliable valid marker of inflammation, stress and infection (bacterial, }\end{array}$ \\
\hline $\begin{array}{l}\text { Automatic \& calculated NLR as a regular and routine parameter of } \\
\text { hemogram, Derive as much information from complete blood count as } \\
\text { possible: NLR, PLR, RDW \%, MDW, MPV, LMR }\end{array}$ & $\begin{array}{l}\text { High-speed response (T1/2 half-life, 6-8-12 hours), dynamic } \\
\text { immunologic parameter. Daily routine use as a part of complete blood } \\
\text { count (hemogram) is recommended }\end{array}$ \\
\hline $\begin{array}{l}\text { Cheap, simple and easily available parameter. } \\
\text { Useful in sorting out patients with severe illness vs. patients with milder } \\
\text { illness. NLR cut-off values should be adopted/refined for each diagnosis (Fig. 2) }\end{array}$ & $\begin{array}{l}\text { Each clinical entity (disease or syndrome) has its own typical profile } \\
\text { of NLR for uncomplicated and complicated course (e.g, cancer, stroke, } \\
\text { acute myocardial infarction, appendicitis, pancreatitis, sepsis) }\end{array}$ \\
\hline $\begin{array}{l}\text { Index of immune-inflammatory response (SIRS), organ dysfunction, } \\
\text { endocrine stress, tissue injury, can be used in various clinical syndromes }\end{array}$ & $\begin{array}{l}\text { Follow-up of intensity of inflammation, low-grade, moderate, severe } \\
\text { and critical (Fig. 2) Hallmark of non-infectious and infectious SIRS, }\end{array}$ \\
\hline $\begin{array}{l}\text { Rapid and dynamic parameter of cellular immune response in } \\
\text { inflammation and infection, can be used in retrospective and prospective } \\
\text { trials for evaluation the severity of disease }\end{array}$ & $\begin{array}{l}\text { NLR for screening subclinical inflammation, warning of severity (on } \\
\text { emergency admission) warning of complications in clinical medicine, } \\
\text { e.g, in surgery, cardiology, neurology, psychiatry, oncology }\end{array}$ \\
\hline $\begin{array}{l}\text { Reflects imbalance between sympathetic/parasympathetic nervous } \\
\text { system (Kalelioglu, 2019) }\end{array}$ & $\begin{array}{l}\text { Stratification according to the severity of disease, monitoring the } \\
\text { response to therapy }\end{array}$ \\
\hline $\begin{array}{l}\text { Measures of severity and/or intensity of immune-inflammation reaction } \\
\text { and stress (Fig. 1) }\end{array}$ & $\begin{array}{l}\text { Hallmark of cancer, measure of CASI, for stratification, prediction and } \\
\text { prognosis (23, 25) }\end{array}$ \\
\hline
\end{tabular}

\section{NLR for stratification of COVID-19 pneumonia and acute re- spiratory failure}

The neutrophil-to-lymphocyte ratio (NLR) is a simple, available and valid index of immune-inflammatory response, neuroendocrine stress and severity of illness. It is a very sensitive but less specific hematologic parameter that reflects the intensity of systemic infection/ inflammation, stress and severity of diseases of various origins, including COVID-19 infection (Zahorec, 2017, 2020). Patients infected with COVID-19 exhibited higher leukocyte counts, abnormal respiratory findings, and mildly or moderately increased plasma levels of proinflammatory cytokines. Patient sputum showed positive polymerase chain reactions for novel coronavirus SARS-CoV-2. The patients with COVID-19 infection had significantly higher values of NLR (5.00; IQR 2.3-13.9) than non-COVID patients (2.7; IQR 1.7-4.7; $\mathrm{p}<0.001)$. Severely ill patients with COVID-19 infection had severe lymphocytopenia, higher NLR ratio ( $\geq 5-7)$, lower platelet counts, higher erythro- cyte sedimentation rate (ESR), mildly to moderately increased Creactive protein and procalcitonin, and elevated $\mathrm{LDH}$, whereas the cytokines such as IL-2, IL4, IL-6, IL-10 and IFN-gamma were not increased or only moderately increased (Song et al, 2020). NLR can be used as an objective parameter for the purpose of stratification of patients with COVID-19 infection (Ma et al, 2020), as well as for monitoring the response to the systemic therapy with IL-1beta antibody - Canakinumab; (Generali et al, 2021). Not only the initial value of NLR and D-dimer levels are important for stratification, the dynamic changes of NLR values during hospital stay are of importance too. A progressive increase in NLR during the clinical course is associated with the severity of COVID-19 disease, and poor clinical outcome (Fu et al, 2020, Ma et al, 2020). The major pathogenesis of viral respiratory infection is inflammation of respiratory pathways, which in case of severe COVID-19 manifests as severe, unilateral or bilateral pneumonia and is associated with severe hypoxemia and dyspnea. Severe cases are coupled with leukocytosis and NLR values increased above 
3.13 (Liu et al, 2020), or above 5.0 (Song et al, 2020). The severe course of COVID-19 is associated with the development of a severe acute respiratory syndrome (SARS). Typical clinical signs of SARS are dyspnea, tachypnea (above 24 breaths/min), severe hypoxemia $\left(\mathrm{SpO}_{2}<86 \%\right)$ and $\mathrm{CT}$-confirmed bilateral pneumonia (Zhou et al, 2020). The bad prognosis of COVID-19 is characterized by ongoing severe bilateral pneumonia, development of acute respiratory failure or ARDS with severe hypoxemia and very low oxygenation index $\left(\mathrm{paO}_{2} / \mathrm{FiO}_{2}<150-100 \mathrm{mmHg}\right)$, which should be treated by non-invasive or artificial mechanical ventilation. Neutrophil-to-lymphocyte ratio is an emerging biomarker of the systemic inflammation and severity of illness, which can be used alone or together with other biomarkers such as D-dimer levels, serum ferritin, lactate dehydrogenase, troponins and blood levels of CRP, PCT, and IL-6 for screening, early diagnosis/stratification and prognosis of COVID-19.

\section{Perspectives and future of neutrophil-to-lymphocyte ratio in clinical practice}

The concept of NLR has brought about a new and deep insight of the dynamic course of immune-inflammatory response as a reaction between innate and adaptive cell immune systems during various pathological states and illnesses. The unique position of NLR as a simple, cheap and easily available parameter is that it reflects the complex relations and physiological cooperation among three suprasystems: vegetative nervous system, neuroendocrine and immune systems. NLR itself integrates the general activity of these suprasystems, however, under clinical condition we cannot differentiate between the contribution of each of them. The clinical interpretation should be very careful, only in clinical context, while taking in mind the influence of the neuroendocrine stress (Kalelioglu, 2019), and many other factors such as anemia, age and comorbidities (Fisher et al, 2019). The normal range of NLR is in the range of $1-2(0.8-2.2)$. The values above 3.0 and below 0.7 in adults are pathological. NLR in grey zone of the range of 2.3-3.0 may serve as a warning that there is a pathological process present in organism, such as cancer, atherosclerosis or ischemic heart disease, psychiatric disorders, subclinical infection and/or inflammation (Fig. 1, Tab. 4). NLR may help clinicians in the process of stating the right diagnosis or deciding for online monitoring of immune-inflammation response or reaction to various insults. The twenty-year experience of using NLR as a prognostic marker provides wealth of evidence for routine clinical use. The parameter of NLR parameter can be used for screening, early warning, stratification according to the severity of disease, prediction and prognosis. However, its correct employment in clinical practice needs few important issues to be accounted for (Tabs 5-7), namely longer time for reading, understanding and right interpretation. NLR assessments should be done at serial time points. The change in NLR ( $\triangle N L R)$ may be used for prediction and prognosis. The heterogeneity of many diseases (cancer, ischemic heart disease) and syndromes (including SIRS and sepsis) are affected by the strong influence of genotype and phenotype (epigenetics). Due to this fact, NLR should be used as part of a panel of other biomarkers (Tabs
3 and 4). NLR is a novel parameter that is opening a new dimension in clinical medicine, while improving the understanding of the biology of inflammation, pathophysiology of cellular immune response, coupling and antagonism between innate and adaptive immunity and its clinical consequences for health and disease. NLR is a novel marker of cellular immune activation, a valid index of stress and systemic inflammatory response syndrome of various origins. The utility of NLR is summarized in Table 8 . It can be used for stratification and evaluation of the severity of disease in many clinical disciplines (Tab. 4). NLR is a cheap, simple and easily available parameter with high sensitivity and lower specificity. It is a dynamic parameter with a quick response to insults, it reflects improvement or deterioration of the clinical status. It can be used as part of a panel with valid biomarkers of infection /inflammation. NLR alone or along with other markers may be helpful in the process of decision making and management of various acute and/or chronic diseases.

\section{References}

1. Abdelaleem NA, Makhouf HA, Nagiub EN, Bayoumi HA. Prognostic biomarkers in predicting mortality in respiratory patients with ventilatorassociated pneumonia. Egyptian J Bronchol 2021; 15: 16.

2. Acaturk G, Acay A, Demir K, Ulu MS et al. Neutrophil-to-lymphocyte ratio in inflammatory bowel disease - as a new predictor of disease severity. Bratisl Med J 2015; 116 (4): 213-217.

3. Aird W. The Hematologic System as a Marker of Organ Dysfunction in Sepsis. Mayo Clin Proc 2003; 78: 869-881.

4. Alexander NI. Reference values of neutrophil-lymphocyte ratio, plateletlymphocyte ratio and mean platelet volume in healthy adults in north central Nigeria. J Blood Lymph 2016; 6: 143-145.

5. Akilli NB, Yortanli M, Mutlu H et al. Prognostic importance of neutrophil-lymphocyte ratio in critically ill patients: short- and long-term outcomes. Am J Emerg Med 2014; 32: 1476-1480.

6. Akpek M, Kaya MG, Lam YY et al. Relation of neutrophil/lymphocyte ratio to coronary flow to in-hospital major cardiac events in patients with ST elevated myocardial infarction undergoing primary coronary intervention. Am J Cardiol 2012; 110 (5): 621-627.

7. An X, Ding PR, Li Y, Wang FH, Shi YX et al. Elevated neutrophil to lymphocyte ratio predicts survival in advanced pancreatic cancer. Biomarkers 2010, 15: 516-522.

8. Angulo M, Moreno L, Aramendi Ig, dos Santos G, Cabrera J, Burghi G. Complete Blood Count and Derived Indices. Evolution Pattern and Prognostic Value in Adult Burned Patients. J Burn Care Res 2020; 41: 1260-1266.

9. Arigami T, Uenosono Y, Matsuhita D, Yanagita S et al. Combined fibrinogen concentration and neutrophil-lymphocyte ratio as a prognostic marker of gastric cancer. Oncol Lett 2016; 11 (2): 1537-1544.

10. Asemota KE, Ekene EN, Ehebha SE, Olowe T. Leukocyte profile of Adult Nigerians as Indicator of severity level of Acute musculoskeletal trauma. Intern Blood Res Rev 2019; 9 (1): 1-9.

11. Aydin I, Agilli M, Aydin FN, Kurt YG, Cayci T, Tas A, Honca T, Kocak N. The reference ranges of neutrophil-lymphocyte ratio in different age groups. Gulhane Med J 2015; 57 (4): 414-418.

12. Azab B, Jaglall N, Atalah J.P, Lamet A, Raja-Surya V et al: Neutrophil-lymphocyte ratio as a predictor of adverse outcomes of acute pancreatitis. Pancreatology 2011; 11 (4): 445-452. 
13. Azab B, Camacho-Rivera M, Taioli E. Average Values and Racial Differences of Neutrophil Lymphocyte Ratio among a Nationally Representative Sample of United States Subjects. PLOS One 2014; 9 (11): e112361.

14. Bateman RTM, Sharpe MD, Singer M, Ellis CG. The Effect of Sepsis on the Erythrocyte. Internat J Mol Sci 2017; 18 (9): 1932-1945.

15. Bhat T, Teli S, Rijal J et al. Neutrophil to lymphocyte ratio and cardiovascular disease: a review. Expert Rev Cardiovasc Ther 2013; 11 (1): 55-59.

16. Bone R, Balk R, Cerra FB, Dellinger RP, Fein AM, Knaus WA, Schein RM, Sibbald WJ. Definitions for sepsis and organ failure and guidelines for the use of innovative therapies in sepsis. The ACCP/SCCM Consensus Conference Committee. Chest 1992; 101 (6): 1644-1655.

17. Boshier P, Sayers R, Hadjiminas DJ et al. Systemic inflammatory response syndrome in a patient diagnosed with high grade inflammatory triple negative breast cancer: a case report of a potentially rare paraneoplastic syndrome. Exp Hematol Oncol 2016; 5: 16.

18. Bowen RC, Little NA, Harmer JR, Ma J, Mirabelli LG et al. Neutrophil-to-lymphocyte ratio as prognostic indicator in gastrointestinal cancers: a systematic review and meta-analysis. Oncotarget 2017; 8: 32171

19. Capone M, Giannareli D, Mallardo D, Madonna G, Festino L, Grimaldi AM et al. Baseline neutrophil- to lymphocyte ratio (NLR) and derived NLR could predict overall survival in patinets with advanced melanoma treated with nivolumab. J ImmunoTher Cancer 2018; 6: 74.

20. Castello A, Rossi S, Toschi L, Mazzioti E, Lopci E. Hyper-progressive Disease in Patients with Non-Small Cell Lung Cancer Treated with Checkpoint Inhibitors: The Role of 18F-FDG PET/CT. J Nucl Med 2019; 61: 821-826.

21. Castello A, Toschi L, Rossi S, Mazzioti E, Lopci E. The immunemetabolic-prognostic index and clinical outcomes in patients with non-small cell lung carcinoma under checkpoint inhibtors. J Cancer Res Clin Oncol 2020; 146: 1235-1243.

22. Celik B, Nalcacioglu H, Ozcatal M, Torun YA. Role of neutrophil-tolymphocyte ratio and platelet-to-lymphocyte ratio in identifying complicated appendicitis in the pediatric emergency department. Ulus Travma Acil Cerrahi Derg 2019; 25 (3): 222-228.

23. Celikbilek A, Ismailogullari S, Zarasiz G. Neutrophil to lymphocyte ratio predicts poor prognosis in ischemic cerebrovascular disease. J Clin Lab Anal 2014; 28: 27-31.

24. Chalupa P, Beran O, Herwald H, Kaspríková N, Holub M. Evaluation of potential biomarkers for the discrimination of bacterial and viral infections. Infection 2011; 39: 411-417.

25. Chen L, Yan Y, Zhu L, Cong X, Li S, Song S, Song H, Xue Y. Systemic immune-inflammation index as a useful prognostic indicator predicts survival in patients with advanced gastric cancer treated with neoadjuvant chemotherapy. Cancer Manag Res 2017; 14 (9): 849-867.

26. Chen ZQ, Yu XS, Mao LJ, Xue LL, Shu J et al. Prognostic value of neutrophil-lymphocyte ratio in critically ill patients with cancer: a propensity score matching study. Clin Transl Oncol 2020.

27. Cho KH, Jeong MH, Ahmed K, Hachonohe D, Choi HS et al. Value of early risk stratification using hemoglobin level and neutrophil-to-lymphocyte ratio in patients with ST elevation myocardial inferction undergoing primar percutaneous coronary intervention. Am J Cardiol 2011; 107: 849-856.

28. Cohen JT, Miren TJ, Vezeridis MP. Is the neutrophil lymphocyte ratio a useful prognostic indicator in melanoma patients? Melanoma Manag 2020; 7 (3): 158-164.

29. Colotta F, Allavena P, Sicca A et al. Cancer-related inflammation: the seventh hallmark of cancer: links to genetic instability. Carcinogenesis 2009; 30 (7): 1073-1081.
30. Crouser ED, Parillo JE, Seymour C, Angus DC, Bicking K et al. Improved Early Detection of Sepsis in the ED with a Novel Monocyte Distribution Width Biomarker. Chest 2017; 152 (3): 518-526.

31. Cupp MA, Cariolou M, Tzoulaki I, Evangelos E, Berlanga-Taylor A. Neutrophil counts and cancer prognosis: an umbrella review of systematic review and meta-analyses of observational studies, 2020; 18: 360 .

32. Curbelo J, Luquero Bueno S, Galván-Román JM et al. Inflammation biomarkers in blood as mortality predictors in community-acquired pneumonia admitted patients: importance of comparison with neutrophil count percentage or neutrophil-lyphocyte ratio. PLoS ONE 2017; 12 (3): e0173947.

33. Dionigi R, Dominioni L, Benevento A, Giudice G et al. Effects of Surgical Trauma of Laparoscopic vs Open Cholecystectomy. Hepato-Gastroenterology 1994; 41: 471-476.

34. Demircan F, Gozel N, Kilme F, Ulu R, Atmaca M. The Impact of Rewd Blood Cell Distribution Width and Neutrophil/Lymphocyte Ratio on th Diagnosis of Major Depressive Disorder. Neurol Ther 2016 5: 27-33.

35. Drobný J. Neutrophil to lymphocyte ratio (NLR) in gynecological disease. Slov Gynekol Pôrod 2020; 27 (3): 124-128.

36. Elebute EA, Stoner HB. The grading of sepsis. Br J Surg 1983; 70: 29-31.

37. Ethier JL, Desautels D, Templeton A et al. Prognostic role of neutrophil-to-lymphocyte ratio in breast cancer: a systematic review and metaanalysis. Breast Cancer Res 2017; 19 (1): 2.

38. Farkas JD. The complete blood count to diagnose septic shock. J Thorac Dis 2020; 12 (S.1): S16-S21.

39. Ferrandino RM, Roof $S$, Garneau J, Haidar J et al. Neutrophil-tolymphocyte ratio as a prognostic indicator for overall and cancer specific survival in squamous cell carcinoma of the head and neck. Head Neck 2020, 42 (10): $2830-2840$

40. Ferrucci PF, Gandini S, Battaghiaish A et al. Baseline neutrophil-tolymphocyte ratio is associated with outcome of ipilimumab-treated metastatic melanoma patients. J Cancer 2015; 112: 1904-1912.

41. Ferruci PF, Ascierto PA, Pigozzo J, Del Vecchio $M$ et al. Baseline neutrophils and derived neutrophil-to-lymphocyte ratio: prognostic relevance in metastatic melanoma patients receiving ipilimumab. Ann Oncol 2017, 27: 732-738.

42. Fisher A, Srikusalanukul W, Fisher L, Smith P. The neutrophil to Lymphocyte Ratio on Admission and Short-term Outcomes in Orthogeriatric Patients. Int J Med Sci 2016; 13 (8): 588-602.

43. Forget $P$, Khalifa C, Defour JP, Latinne D, Van Pel MC, De Kock M. What is the normal value of the neutrophil-to-lymphocyte ratio. BMC Res Notes 2017; 10: 12.

44. Forget P, Moreau N, Engel H, Cornu O, Boland B, De Kock M et al. The neutrophil-to-lymphocyte ratio (NLR) after surgery for hip fracture (HF). Arch Gerontol Geriatr 2015; 60: 366-371.

45. Fu J, Kong J, Wang W, Wu M, Yao $L$ et al. The Clinical Implication of dynamic Neutrophil to lymphocyte ratio and D-dimer in COVID-19: A retrospective study in Shuzou China. Thrombosis Res 2020; 192: 3-8.

46. Generali D, Bosio G, Malberti F, Cuzzoli A, Testa S, Romanini L et al. Canakinumab as treatment for COVID-19-related pneumonia: a prospective case-control study. Intern J Infect Dis 2021; 104: 433-440..

47. Giede-Jeppe A, Bobinger T, Gerner S.T, Sembill J.A, et al. Neutrophilto-Lymphocyte Ratio is an Independent Predictor for In-hospital Mortality in Spontaneous Intracerebral Hemorrhage. Cerebrovasc Dis 2017: 44: 26-34.

48. Grivennikov SI, Greten FR, Karin M. Immunity, inflammation, and cancer. Cell 2010; 140 (6): 883-899. 
49. Gucyetmez B, Atalan HK. C-reactive protein and Hemogram Parameters for the Non-Sepsis Systemic Inflammatory Response Syndrome and Sepsis: What Do they Mean? PLOS One 2016; 11 (2): e0148699.

50. Guthrie GJK, Charles KA, Roxburgh CS, Horgan PHG, McMillan DC. The systemic inflammation-based neutrophil-lymphocyte ratio: Experience in patients with cancer. Crit Rev Oncol Hematol 2013; 88: 218-230.

51. Halazun KJ, Aldoori A, Malik HZ, Al-Mukhtar A, Prasad KR, Toogood GJ, Lodge JPA. Elevated preoperative neutrophil to lymphocyte ratio predicts survival following hepatic resection for colorectal liver metastases. Eur J Surg Oncol (EJSO) 2008; 34: 55-60.

52. Ham SY, Yoon HY, Nam SB, Yun BY, Eum D, Shin ChS. Prognostic value of neutrophil/lymphopcyte ratio and mean platelet volume/platelet ratio for 1-year mortality in critically ill patients. Sci Reports 2020; 10: 21513.

53. Hedayat K, Lapraz JC. The Theory of Endobiogeny: Global System Thinking and Biological Modeling for Clinical Medicine. Academic Press, Philadelphia, 2019, volume 1.

54. Hedayat K. The theory of endobiogeny: biological modeling using downstream physiologic output as interference of upstream global system regulation. J Complexity Health Sci 2020; 3 (1): 1-8.

55. Heffernan DS, Monaghan SF, Thakkar RK, Machan JT, Cioffi WG, Ayala A. Failure to normalize lymphopenia following trauma is associated with increased mortality, independent of the leukocytosis pattern. Crit Care 2012; 16: R12.

56. Holub M, Beran O, Kaspř́íková $\mathbf{N}$, Chalupa $P$. Neutrophil to lymphocyte count ratio as a biomarker of bacterial infections Central Eur J Med 2012; 7 (2): 258

57. Howard R, Kanetsky PA, Egan KM. Exploring the prognostic value of the neutrophil-to-lymphocyte ratio in cancer. Sci Rep 2019; 9: 19673.

58. Hotchkiss RS, Moldawer LL, Opal SM, Reinhart K et al. Sepsis and Septic Shock. Nat Rev Dis Primers 2016; 2: 16045. DOI: 10.1038.

59. Hotchkiss RS, Moldawer LL. Parallels between Cancer and Infectious Disease. NEJM 2014; 371: 380-383.

60. Huang L, Chen L, Yang L, Wan R, Hu G, Neutrophil-to-lymphocyte ratio can specifically predict the severity of hypertriglyceridemia-induced acute pancreatitis compared with white blood cells. J. Clinical Lab Analysis 2019; 33 (4): e22839

61. Hwang SY, Shin TG, Jo JJ, Jeon K, Suh GY, Lee TR et al. Neutrophilto-lymphocyte ratio as a prognostic marker in critically ill septic patients. Am J Emerg Med 2017; 35: 234-239.

62. Idowu OK, Ding Q, Chandrasekar CE, Taktak AFG, Yin Q. Clinical implication of pretreatment neutrophil to lymphocyte ratio in soft tissue sarcoma. Biomarkers 2012. DOI: 10.3109/1354750X.2012.

63. Imran MM, Ahmed U, Usman U, Ali M, ShaukaT A, Gul N. Neutrophil/lymphocyte ratio - A marker of COVID-19 pneumonia severity. Internat. J Clin Practice 2021; e13698.

64. Inci K, Kahn BS, Turkoglu M, Aygencel G. Prognostic Value of Red Cell Distribution Width and Neutrophil-Lymphocyte Ratio on Admission in Critically Ill Patients: A retrosopective cohort Study. Egypt J Crit Care Med 2020; 7 (3): 92-97.

65. Ishihara M, Ochiai R, Haruyama T, Sakamoto T, Tanzawa $S$ et al. Pretreatment neutrophil-to-lymphocyte ratio predicts treatment efficacy and prognosis of cytotoxic anticancer drugs, molecular targeted drugs, and immune check points inhibitors in patients with advanced non-small cell lung carcinoma. Transl Lung Cancer Res 2021; 10 (1): 221-232.

66. Ishizuka M, Shimizu T, Kubota K. Neutrophil-to-lymphocyte ratio has a close association with gangrenous appendicitis in patients undergoing appendectomy. Int. Surg 2012; 97: 299-304.
67. Ishizuka M, Oyama Y, Abe A, Kubota K. Combination of platelet count and neutrophil to lymphocyte ratio is a useful predictor of postoperative survival in patients undergoing surgery for gastric cancer. J Surg Oncol 2014; 110 (8): 935-941.

68. Jankova L, Dent O.F, Chan C, Chapuis P, Clarke S. Preoperative neutrophil/lymphocyte ratio predicts overall survival but does not predict recurrence or cancer -specific survival after curative resection of nodepositive colorectal cancer. BMC Cancer 2013; 13: 442.

69. de Jager C, van Wijk PT, Mathoera RB, de Jongh-Leuvenink J, van der Poll T, Wever PC. Lymphocytopenia and neutrophil-lymphocyte count ratio predict bacteremia better than conventional infection markers. Crit Care 2010; 14 (5): R192.

70. Kahramaca S, Ozgehan G, Seker D, Gokce EL, Seker G et al. Neutrophil-to-lymphocyte ratio as a predictor of acute appendicitis. Ulusa travma Acil Cerrahi Derg 2014; 20: 19-22.

71. Kalelioglu T, Karamustafalioglu N. A new interpretation of neutrophil-lymphocyte ratio from psychiatric aspect. Bratisl Med J 2019; 120 (8): 604-605.

72. Kang HJ, Bae K, Kim JH et al. Correlation between Natural Killer Cell Activity and Systemic Inflammatory Markers for Heterogenous Cancer Patients treated with Wheel Balance Cancer Therapy. Integrative Cancer Ther 2017

73. Kantola T, Klintrup K, Vayrynen JP, Vornanen J Bloigu R et al. Stage dependent alterations of the serum cytokine pattern in colorectal carcinoma. Br J Cancer 2012; 107 (10): 1729-1736.

74. Karaman K, Celik Ci, Fidan E, Oskay A. The neutrophil lymphocyte ratio may predict patients admitted to the emergency department. Med Sci Discov 2020; 7 (3): 422-425.

75. Karamustafalioglu N, Kalelioglu T, Celikel G, Genc A, Emul M. Clinical utility of neutrophil-lymphocyte ratio in the diagnosis of neuroleptic malignant syndrome. Nord J Psychiatry 2019; 73 (4-5): 288-292.

76. Kaushik R, Gupta M, Sharma $M$ et al. Diagnostic and Prognostic Role of Neutrophil-to-Lymphocyte Ratio in Early and Late Phase of Sepsis. Indian J Crit Care Med 2018; 22 (66): 38-41.

77. Kokulu K, Gunaydin YK, Akilli B, Koylu R et al. Relationship between the neutrophil-to-lymphocyte ratio in acute pancreatitis and the severity and systemic complictions of thr disease. Turk J Gastroenterol 2018; 29 (6): 684-691.

78. Kong W, He Y, Bao H, Zhang W, Wang X. Diagnostic Value of Neutrophil-Lymphocyte Ratio for Predicting the Severity of Acute Pancreatitis: A Meta-Analysis. Dis Markers 2020. ID 9731854.

79. Korkmaz P, Eraslan S, Toka O et al. Evaluation of the Association Between the Neutrophil to lymphocyte ratio and Mortality in the Patients Followed up with the Diagnosis of Sepsis. J Clin Analyt Med 2016.

80. Kulaksizoglu S, Koparan C. High neutrophil to lymphocyte ratio and low mean platelet volume level in autism spectrum disorders. Annals Med Res 2019; 26 (10): 2382-2385.

81. Lattanzi S, Cagnetti C, Provinciali L, Silvestrini M. Neutrophil-toLymphocyte Ratio predicts the outrcome of Acute Intracerebral Hemorrhage. Stroke 2016; 47 (6): 1654-1657.

82. Lee JS, Kim NY, Na SH, Youn YH, Shin CS. Reference values of neutrophil-lymphocyte ratio, lymphocyte-monocyte ratio, platelet-lymphocyte ratio, and mean platelet volume in healthy adults in South Korea. Medicine 2018; 97: e11138.

83. Liu X, Shen Y, Wang H, Ge Q et al. Prognostic significance of neutrophil-to-lymphocyte ratio in patients with sepsis: a prospective observational study. Mediators Inflamm 2016; 16: 8191254. 
84. Liu G, Ke LC, Sun RC. Prognostic value of pretreatment neutrophilto-lymphocyte ratio in patients with soft tissue sarcoma: A meta-analysis. Medicine (Baltimore) 2018; 97 (36): e12176.

85. Liu JY, Liu Y, Xiang P, Pu L, Xing HF et al. Neutrophil to-lymphocyte ratio predicts severe illness patients with 2019 Novel Corona virus in Early stage. medRxiv 2020.

86. Ljungstrom L, Pernestig AK, Jacobsson G et al. Diagnostic accuracy of procalcitonin, neutrophil-lymphocyte count ratio, C-reactive protein, and lactate in patients with suspected bacterial sepsis. PLoS One 2017; 12 : e0181704.

87. Loonen AJM, de Jager CP, Tosserams J, Kusters R, Hilbink M, Wever PC et al. Biomarkers and Molecular Analysis to Improve Blood stream Infection Diagnostics in the Emergency department. Plos One 2014; 9(1): e 87315

88. Luo Y, Shi X, Li W, Mo L, Yang Z, Li X, Qin L, Mo W. Evaluation of the clinical value of hematological parameters in patients with urothelial carcinoma of the bladder. Medicine 2018; 97 (14).

89. Ma Y, Shi N, Fan Y, Wang J et al. Predictive Value of Neutrophil-tolymphocyte ratio (NLR) for Diagnosis and Worse Clinical Course of the COVID-19. Findings from Ten Provinces of China. Lancet 2020.

90. Mantovani A, Allavena P, Sica A, Balkwill F. Cancer-related inflammation. Nature 2008; 454: 436-444.

91. Marik PE, Stephenson E. The ability of Procalcitonin, lactate, white blood cell count and neutrophil-lymphocyte count ratio to predict blood stream infection. Analysis of a large database. J Crit Care 2020; 60 (12): 135-139.

92. Malietzis G, Giacometti M, Askari A et al. A preoperative neutrophilto-lymphocyte ratio of 3 predicts free survival after curative elective colorectal cancer surgery. Ann Surg 2014; 260 (2): 287-292.

93. Mazza MG, Lucchi S, Tringali AGM, Rossetti A et al. Neutrophil/ lymphocyte ratio and platelet/lymphocyte ratio in mood disorders: A metaanalysis. Progr Psychopharmacology and Biol Psych 2018; 84: 229-236.

94. Mazza MG, Lucchi S, Rossetti A, Clerici M. Neutrophil lymphocyte ratio, monocyte-lymphocyte ratio, and platelet-lymphocyte ratio in nonaffective psychosis: A meta-analysis and systematic review. World J Biol Psych 2020; 21 (5): 326-338

95. McMillan DC, Canna K, McArdle CS. Systemic inflammatory response predicts survival following curative resection of colorectal cancer. Br J Surg 2003; 90: 215-219.

96. Mei Z, Shi L, Bo W, Wei Y. Prognostic role of pretreatment blood neutrophil-to-lymphocyte ratio in advanced cancer survivors: A systematic review and meta-analysis of 66 cohort studies. Cancer Treatment Reviews 2017 May.

97. Millrud Rydberg C. Pattern recognition receptors and neutrophils in cancer inflammation. PhD Thesis, Karolinska Universitet, Solna 2012, Sweden.

98. Mohamed Z, Pinato D.J, Mauri FA et al. Inflammation as a validated prognostic determinant in carcinoma of unknown primar site. $\mathrm{Br} \mathrm{J}$ Cancer 2014; 110: 208-213.

99. Motomura T, Shirabe K, Mano Y, Muto J, Toshima T, Umemoto $\mathbf{Y}$ et al. Neutrophil-lymphocyte ratio reflects hepatocellular carcinoma recurrence after liver transplantation via inflammatory microenvironment. J Hepatol 2013; 58 (1): 58-64.

100. Mubder M, Dhindsa B, Nguyen D, Saghir S et al. Utility of inflammatory markers to predict adverse outcome in acute pancreatitis: A retrospective study in a single academic center Saudi J Gastroenterol 2020; 26 (4): 216-221.

101. Nestor D, Andersson H, Kihlberg P, Olson S, Ziegler I et al. Early prediction of blood stream infection in a prospective collected cohort. BMC Infectious Dis 2021; 21: 316.
102. Ohno Y, Nakashima J, Ohori M, Hatano T, Tachibana M. Pretreatment neutrophil-to-lymphopycte ratio as an independetn predictor of recurrence in patients with non-metastatic renal cell carcinoma. J Urol 2010; 184: 873-878.

103. Ohno Y, Nakashima J, Ohori M, Gondo T, Hatano T. Follow-up of Neutrophil-to-lymphocyte Ratio and Recurrence of Clear Cell Renal Cell Carcinoma. J Urol 2012; 187 (2): 411-417.

104. Orphanu A, Popescu C, Tiliscan C, Streinu-Cercel A, Arama V, Sorin Arama S. The usefulness of neutrophil/lymphocyte count ratio in the diagnosis and prognosis of bacterial sepsis - An old parameter with new implications. Rev Romana Med Lab 2020; 28 (1): 39-48.

105. Ozgen E, Guzel M, Akpinar CE, Yucel M, Demir MT, Baydin A. The relationship between neutrophil/lymphocyte, monocyte/lymphocyte, platelet/ lymphocyte ratios, and clinical outcomes after ninety days in patients who were diagnosed as having acute ischemic stroke in the emergency room and underwent mechanical thrombectomy. Bratisl Med J 2020; 121 (9): 634-639.

106. Palaj J, Kečkeš Š, Marek $\mathbf{V}$ et al.Fibrinogen levels are associated with lymph node involvement and overall survival in gastric cancer patients. Anticancer Res 2018; 38 (2): 1097-1104.

107. Pan W, Zhao D, Zhang C, Li W, Yu J et al. Application of neutrophil/ lymphocyte ratio in predicting coronary blood flow and mortality in patients with ST-elevation myocardial infarction undergoing percutaneous coronary intervention. J Cardiol 2014; 10: 10-14.

108. Park JS, Seo KW, Choi B-, Choi SY.et al. Importance of prognostic value of neutrophil to lymphocyte ratio in patients with ST-elevation myocardial infarction. Medicine (Baltimore) 2018; 97 (48): e13471.

109. Paramanathan A, Saxena A, Morris DL. A systematic review and meta-analysis on the impact of preoperative neutrophil lymphocyte ratio on long term outcomes after curative intent resection of solid tumours. Surg Oncol 2014; 23 (1): 31-39.

110. Paulson R.F, Ruan B, Hao S, Chen Y. Stress Erytropoiesis is a Key Inflammatory Response. Cells 2020; 9 (3): 634.

111. Pichler M, Hutterer GC et al. Validation of the pre-treatment neutrophil-lymphocyte ratio as a prognostic factor in a large European cohort of renal cell carcinoma patients. Brit J Cancer 2013; 108: 901-907.

112. Pinato DJ, Stavraka Ch, Flynn MD, Forster M, Cathail SM. An Inflammation Based Score Can optimize the Selection of Patients with Advanced Cancer considered for early Phase of Clinical trials. Plos One 2014; 9 (1): e83279.

113. Proctor MJ, McMillan DC, Morrison DS, Fletcher CD, Horgan PG Clarke SJ. A derived neutrophil to lymphocyte ratio predicts survival in patients with cancer. Brit J Cancer 2012; 107 (4): 695-699.

114. Rashid F, Waraich N, Bhatti I, Saha S, Khan RN et al. A pre-operative neutrophil:lymphocyte ratio does not predict survival from oesophageal cancer resection. World J Surg Oncol 2010; 8 (1): 5-11.

115. Reiske L, Schmucker S, Pfaffinger B, Weiler U, Steuber J, Stefanski V. Intravenous Infusion of Cortisol, Adrenaline, or Noradrenaline Alters Porcine Immune Cell Numbers and Promotes Innate over Adaptive Immune Functionality. J Immunol 2020 May.

116. Riché F, Gayat E, Barthelémy $R$ et al. Reversal of neutrophil-tolymphocyte count ratio in early versus late death from septic shock. Crit Care 2015; 19: 439.

117. Rimmelé Th, Payen D, Cantaluppi V, Marshall J et al. Immune Cell Phenotype and Function in Sepsis. Shock 2016; 45 (3): 282-291.

118. Qiu L, Jin X, Wang JJ et al. Plasma Neutrophil-to-Lymphocyte Ratio on the Third Day Postburn is Associated with 90-day Mortality among Patients with Burns over $30 \%$ of Total Body Surface Area in Two Chinese Burns Centers. J Inflamm Res 2021; 14: 519-526. 
119. Salciccioli JD, Marshall DC, Pimentel MA et al. The association between the neutrophil-to-lymphocyte ratio and mortality in critical illness: an observational cohort study. Crit Care 2015; 19: 13.

120. Sari R, Karakurt Z, Ay M, Celik ME et al. Neutrophil to lymphocyte ratio as a predictor of treatment response and mortality in septic shock patients in the intensive care unit. Turk J Med Sci 2019; 49: 1-14.

121. Sato Y, Gonda K, Harada M, Tanisaka $Y$ et al. Increased neutrophil lymphocyte ratio is a novel marker of nutrition, inflammatuion and chemotherapy outcome in patients with locally advanced and metastatic esophageal squamous ceôll carcinoma Biomed Reports 2017; 7 (1): 79-84.

122. Seban RD, Assié JB, Giroux-Leprieur E, Massiani MA, Soussan M, Bonardel G et al. Association of ther Metabolic Score Using Baseline FDGPET/CT and dNLR with Immunotherapy Outcomes in Advancved NSCLC Patients Treated with First-Line Pembrolizumab. Cancers 2020; 12: 2234.

123. Sen P, Demirdal T, Nemli SA, Vardar I et al. Infection markers as predictors of Bacteremia in an Intensive Care Unit: A prospective study. Pak J Med Sci 2018; 34 (6): 1517-1524.

124. Shi Q, Gao Z, Wu P, Heng F et al. An enrichment model using regular health examination data for early detection of colorectal cancer. Chin J Cancer Res 2019; 31 (4): 686-698.

125. Shindo Y, Hazama S, Tsunedomi R, Suzuki N, Nagano H. Novel Biomarkers for Personalized Cancer Immunotherapy. Cancer 2019; 11: 1223.

126. Song CY, Xu J, He JQ, Qiang Lu Y. COVID-19 early warning score: a multiparameter screening tool to identify highly suspected patients. MdRXiv 2020 .

127. Streltsova EI, Peshkova IV, Samatov IY, Valeeva VA, Vereshchagin EI. Lymphopenia as a determinant factor of sepsis severity, as an exact diagnostic criterion, and as an object of therapy. J Siber Med Sci 2020; 3: $108-125$.

128. Strumfa I, Bogdanova T, Kalva A, Strumfs B, Rumba R, Vanags A, Drike I et al. Systemic Inflammatory Reaction in Gastric Cancer: Biology and Practical Implications of Neutrophil to Lymphocyte ratio, Glasgow Prognostic Score and Related Parameters, chapter 8, p. 143-197. In Gastric Cancer, eds. G. Mózsik, O. Karádi. InTech Rijeka 2017.

129. Sun X, Wang J, Liu J, Chen S, Liu X. Albumin concentrations plus neutrophil lymphocyte ratios for predicting overall survival after curative resection for gastric cancer. Onco Targets Ther 2016; 9: 4661-4669.

130. Suppiah A, Malde D, Arab T, Hamed T, Allgar V et al. The prognostic value of the neutrophil-lymphocyte ratio (NLR) in acute pancreatitis: Identification of an optimal NLR. J Gastrointestin Surg 2013; 17: 675-681.

131. Szkandera J, Gerger A, Liegl-Atzwanger B, Stotz M, Samonigg H, Friesenbichler J, Stojakovic T et al: The derived neutrophil/lymphocyte ratio predicts poor clinical outcome in soft tissue sarcoma patients. Am J Surg 2015; 210 (1): 111-116.

132. Tamhane UU, Aneja S, Montgomery D, Rogers EK, Eagle KA et al. Association between admission neutrophil to lymphocyte ratio and outcomes in patients with acute coronary syndrome. Am J Cardiol 2008; 102 (6): 653-657.

133. Tan YG, Eu EE, On Kam LW, Huang HH. Pretreatment neutrophilto-lymphocyte ratio predicts worse survival outcomes and advanced tumor staging in patients undergoing radical cystectomy for bladder cancer. Asian J Urology 2017; 4 (4): 239-246.

134. Temiz A, Albayrak A, Peksoz R, Disci E, Korkut E et al. Factors affecting the mortality at patients with burns : Single center results. Ulus Travma Acil Cerrahi Derg 2020; 26 (5): 777-783.
135. Toft $\mathbf{P}$, Svendsen $\mathbf{P}$, Tommesen $\mathbf{E}$ et al. Redistribution of lymphocytes after major surgical stress. Acta Anaesth Scand 1993; 37 (3): 245-249.

136. Toktas O, Aslan M, Mean platelet volume, red cell distribution width, neutrophil to lymphocyte ratio and platelel to lymphocyte ratio in the diagnosis of acute appendicitis. East J Med 2017; 22 (1): 5-9.

137. Tomita M, Shimizu T, Ayabe T, Yonei A, Onitsuka T. Preoperative neutrophil to lymphocyte ratio as a prognostic predictor after curative resection for non-small cell lung cancer. Anticancer Res 2011; 31: 2995-2998.

138. Walsh SR, Cook EJ, Goulder F, Justin TA, Keeling NJ. Neutrophillymphocyte Ratio as a Prognostic Factor in Colorectal Surgery. J Surg Oncol 2005; 91: 181-184.

139. Wang Z, Tian S, Zhao K, Zhang R. Yin Y et al. Neutrophil to lymphocyte ratio and fracture severity in young and middle-aged patients with tibial plateau fractures. Intern. Orthop 2020; 44: 2769-2777.

140. Wang F, Wang L, Jiang TT, Xu F et al. Neutrophil-to-lymphocyte ratio is an independent predictor of 30-Day mortality of Intracerebral Hemorrhage Patients. A Validation Cohort Study. Neurotox Res 2018; 34 (3): 347-352.

141. Yoldas H, Karagoz I, Nur Ogun M et al. Novel Mortality markers for Critically ill patients. J Intens Care Med 2018.

142. Yoshida D, Minami K, Morita M, Matsukuma A, Toh Y et al. Prognostic Impact of the Neutrophil-to-Lymphocyte Ratio in Stage I-II Rectal Cancer Patients. J Surg Res 2020; 245 (1): 281-287.

143. Yu Y, Qian L, Cui J. Value of neutrophil-to-lymphocyte ratio for predicting lung cancer prognosis: a meta-analysis of 7,219 patients. Mol Clin Oncol 2017; 7 (3): 498-506.

144. Yu S, Wu D, Jin K, Fu Y et al. Low serum ionized calcium, elevated high sensitive $\mathrm{C}$ reactive protein, Neutrophil-Lymphocyte ratio, and body mass index (BMI) are the risk factors for severe acute pancreatitis in patients with hypertriglyceridemia pancreatitis. Med. Sci Monitor 2019; 25 : 6097-6103.

145. Zahorec R. Definition for sepsis syndrome should be re-evaluated. Intens Care Med 2000; 26 (12): 1870.

146. Záhorec R, Misianik J, Setvak D. Early changes of neutrophil and lymphocyte counts and serum procalcitonin following surgery, SIRS and sepsis. Intens Care Med 2000; 26 (Suppl 3): 227 (43).

147. Zahorec R. Ratio of neutrophil to lymphocyte count - rapid and simple parameter of stress and systemic inflammation in critically ill. Bratisl Med J 2001; 102 (1): 5-14.

148. Záhorec R. Neutrophil-to-lymphocyte ratio. Sixteen-year long history since publication of our article in Bratislava Medical Journal. Bratisl Med J 2017; 118 (6): 321-323.

149. Zahorec R, Hulín I, Záhorec P. Rationale Use of Neutrophil-to-lymphocyte ratio for early diagnosis and stratification of COVID-19. Bratisl Med J 2020; 121 (7): 466-470.

150. Zaragoza J, Caille A, Beneton N, Bens G et al. High neutrophil to lymphocyte ratio measured before starting ipilimumab treatment is associated with reduced overall survival in patients with melanoma. Brit J Dermatol 2016; 174: 146-151.

151. Zhou T, Zheng N, Li X, Zhu D, Han Y. Prognostic value of neutrophillymphocyte count ratio (NLCR) among adult ICU patients in comparison to APACHE II score and conventional inflammatory markers: a multi center retrospective cohort study. BMC Emergency Med 2021; 21: 24.

Received January 31, 2021. Accepted February 21, 2021. 